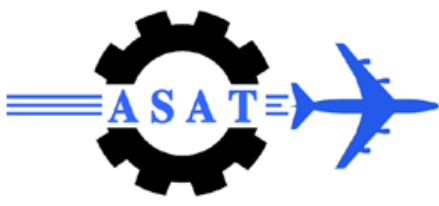

\title{
Performance Evaluation of Homing Guidance Methods
}

\author{
G.A. El-Sheikh ${ }^{*}$
}

\begin{abstract}
A guided missile must be endowed with sufficient intelligence to acquire information for keeping it on course to the target, whether it was stationary or mobile. The guidance commands are generated to control the missile motion relative to target in accordance to the observed and estimated parameters for target motion. The necessity for guiding the missile motion is given by (1) the need to compensate for the non-standard conditions of the medium, technology, propulsion for the achievement of the desired accuracy, especially at greater ranges, (2) the need of reacting on the target maneuver during its flight, and (3) the need for conducting fire behind terrain undulations and artificial obstacles. According to the guidance and control philosophy utilized to control the missile motion and the location of the guidance computer, there are five types of guidance: Homing guidance, Autonomous guidance, Beam rider guidance, Command guidance and Combined guidance systems.
\end{abstract}

The Homing Guidance may be active using onboard transceiver to provide the guidance signals, semi-active which combines an onboard receiver with external illuminator and passive which home on energy generated by the target. The performance of the guidance system is dependent upon the utilized guidance method which constraints the vehicles attitude during its flight. Therefore, this paper is devoted to evaluate the performance of homing guidance methods via the solution of the derived equations of c.g. motion in conjunction with ideal bond equations either numerically or analytically. The guidance performance is analyzed via flight path parameters obtained from the equations' solution. Note that the analytical solution can be very complex unless some simplifying assumptions are considered such as planer motion, constant speeds, etc. Then, the obtained equations are programmed as functions within the MATLAB environment (or any high level language) and the simulation is conducted using different engagements' scenarios. The results justify the capabilities of each guidance method according to the engagement scenario and it will be of great value to young researchers and designers.

Keywords: Guidance and Control, Homing Guidance

\section{Kinematics of Guided Missile Motion}

Homing guided missiles include the following subsystems: (1) a propulsion system, (2) a warhead section, (3) a guidance system, and (4) seeker or homing head (e.g. radar, infrared, imaging IR, electro-optical, lasers). Homing guidance may be of the active, semiactive, or passive type. A passive missile utilizes radiation originated by the target, or by some other source not part of the overall weapon system. Active guidance missiles are able to guide themselves independently after launch to the target and consequently they are of the so-called launch-and-leave or fire-and-forget class. Therefore, an active guided missile carries the

\footnotetext{
*Professor, gaelsheikh@gmail.com, Tel. 0201002682402
} 
radiation source (transceiver) on board the missile. The radiation from the interceptor missile is radiated, strikes the target, and is reflected back to the missile. Thus, the missile guides itself on this reflected radiation. A semiactive missile uses a combination of active and passive guidance; a source of radiation is part of the system external to the missile. The source of radiation is usually at the launch point and it radiates energy to the target, whereby the energy is reflected back to the missile on which the missile homes.

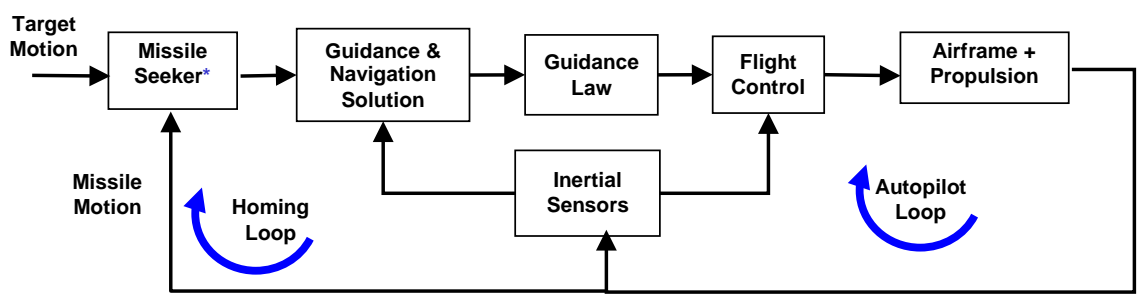

Fig. 1 Homing Missile Guidance and Control

The guidance commands obtained from the guidance system are applied to movable control surfaces which are deflected in order to direct the missile in flight such that it is placed on the proper trajectory to intercept the target. The guidance and control design necessitates modeling including the kinematic and dynamic approaches augmented with programs built under any of the high level or simulation languages for flight analysis and performance evaluation, Fig. 1. The missile motion can be categorized into translatory and rotary motion each of which is divided into kinematic and dynamic motion of, respectively, missile c.g. and missile rotation around its c.g. The whole set of equations representing the guided missile motion describes the missile modeling and can be used for autopilot and guidance designs with further investigation.

Therefore, the paper presents the homing guidance in a way appropriate for those who wish to grasp sound knowledge of guided weapons or autonomous vehicles and their control. It is equally relevant to undergraduate, graduate students, soldiers and engineers involved in developing and manufacturing of guided weapons and robotics or autonomous vehicles. Then, it is devoted to the derivation of the equations describing the vehicle's c.g. motion complemented by equations representing the demanded normal acceleration and miss distance. These equations are solved towards flight path simulation and analysis using different guidance methods. Note that the kinematic analysis of a guided missile motion manipulates this motion ideally without considering the acting forces and consequently the missile is replaced by a massless point moving with known velocity. Then the geometrical characteristics of its motion related to target are to be solved via the law of ideal bonds (guidance). The law of ideal bonds is a geometrical condition imposed upon the missile motion during its flight i.e. this constraint has to be kept through its flight. The ideal bond equations can be expressed by measuring the relative coordinates of missile and target and later it might be named law of control due to its use to actuate the missile control surfaces.

\subsection{Kinematic Equations of Missile c.g. Motion}

The position of the missile with respect to target is determined in polar coordinate-system by radius vector $\overline{\mathrm{D}}$ according to Fig. 2 and the principle law of motion is given by:

$$
\frac{\mathrm{d} \overline{\mathrm{D}}}{\mathrm{dt}}=\overline{\mathrm{V}}_{\mathrm{T}}-\overline{\mathrm{V}}_{\mathrm{M}}
$$

where; $\overline{\mathrm{D}}, \overline{\mathrm{V}}_{\mathrm{T}}, \overline{\mathrm{V}}_{\mathrm{M}}$ are, respectively, the missile-target LOS, target velocity and missile velocity. Since both magnitude and direction of the vector $\overline{\mathrm{D}}$ are functions of time, then the first derivative of $\overline{\mathrm{D}}$ has the form: 


$$
\frac{\mathrm{d} \overline{\mathrm{D}}}{\mathrm{dt}}=\frac{\mathrm{d}\left\{\mathrm{D} \hat{\mathrm{D}}_{\mathrm{o}}\right\}}{\mathrm{dt}}=\dot{\mathrm{D}} \hat{\mathrm{D}}_{\mathrm{o}}+\bar{\omega}_{\mathrm{D}} \otimes \overline{\mathrm{D}}
$$

where $\bar{\omega}_{\mathrm{D}}$ is the angular rate of change of the LOS. Thus, the vector form (1) can be replaced by the component form in the radial direction and two normal directions as follows:

$$
\overline{\mathrm{V}}_{\mathrm{T}}-\overline{\mathrm{V}}_{\mathrm{M}}=\dot{\mathrm{D}} \hat{\mathrm{D}}_{\mathrm{o}}+\bar{\omega}_{\mathrm{D}} \otimes \overline{\mathrm{D}}
$$

It follows from $\mathrm{Eq}^{\mathrm{n}}$ (3) that the motion of a missile to the target can be limited in the radial direction and in two normal directions. Practically, the radial component of the change in range can be influenced only by the change of the engine thrust. Therefore, the motion control is usually limited only in lateral directions and consequently there are only two ideal bond equations and instead of guiding the missile to the point of interception (hit) it will be guided on the curve of interception at the end of which it must hit the target.

The scalar kinematic equations are obtained by specifying a reference frame along its axes the vector form (3) is projected. Since the objective is to minimize the distance between missile and target to zero for interception, the directions of increasing/ decreasing (radial and

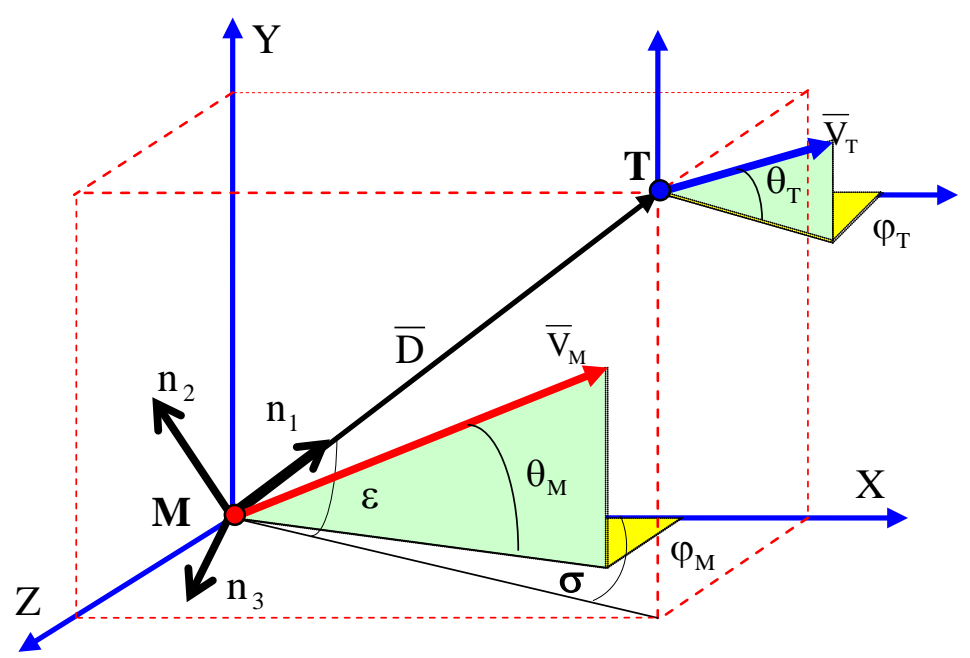

Fig. 2 Geometry of homing guidance lateral) this distance are used to establish the required frame of reference. That is, one along the unit vector $\hat{D}_{o}\left(\hat{n}_{1}\right)$, the second is perpendicular to it in the plane of $\varepsilon\left(\hat{n}_{2}\right)$ and the third is perpendicular to the plane of $\hat{n}_{1}-\hat{n}_{2}$ which is in the plane of $\sigma\left(\hat{n}_{3}\right)$. The components of the vector $\overline{\mathrm{D}}$ along these directions are $[\dot{\mathrm{D}}, \mathrm{D} \dot{\varepsilon}, \mathrm{D} \cos \varepsilon \dot{\sigma}]$. These components can be obtained through the vectorial derivative as follows:

$$
\begin{aligned}
& \bar{\omega}_{\mathrm{D}}=\dot{\bar{\varepsilon}}+\dot{\bar{\sigma}}=\dot{\varepsilon} \hat{\mathrm{n}}_{3}-\dot{\sigma} \sin \varepsilon \hat{\mathrm{n}}_{1}-\dot{\sigma} \cos \varepsilon \hat{\mathrm{n}}_{2} \Rightarrow \bar{\omega}_{\mathrm{D}} \otimes \overline{\mathrm{D}}=\mathrm{D} \dot{\varepsilon} \hat{\mathrm{n}}_{2}+\mathrm{D} \dot{\sigma} \cos \varepsilon \hat{\mathrm{n}}_{3} \\
& \Rightarrow \frac{\mathrm{d} \overline{\mathrm{D}}}{\mathrm{dt}}=\dot{\mathrm{D}} \hat{\mathrm{n}}_{1}+\mathrm{D} \dot{\varepsilon} \hat{\mathrm{n}}_{2}+\mathrm{D} \dot{\sigma} \cos \varepsilon \hat{\mathrm{n}}_{3}
\end{aligned}
$$

Similarly, the other side of $\mathrm{Eq}^{\mathrm{n}}$ (3) can be projected along the reference directions as follows: $\bar{V}_{M}=V_{M} \cos \left(\sigma-\varphi_{M}\right) \cos \left(\varepsilon-\theta_{M}\right) \hat{n}_{1}-V_{M} \cos \left(\sigma-\varphi_{M}\right) \sin \left(\varepsilon-\theta_{M}\right) \hat{n}_{2}-V_{M} \sin \left(\sigma-\varphi_{M}\right) \cos \theta_{M} \hat{n}_{3}$ $\overline{\mathrm{V}}_{\mathrm{T}}=\mathrm{V}_{\mathrm{T}} \cos \left(\sigma-\varphi_{\mathrm{T}}\right) \cos \left(\varepsilon-\theta_{\mathrm{T}}\right) \hat{\mathrm{n}}_{1}-\mathrm{V}_{\mathrm{T}} \cos \left(\sigma-\varphi_{\mathrm{T}}\right) \sin \left(\varepsilon-\theta_{\mathrm{T}}\right) \hat{\mathrm{n}}_{2}-\mathrm{V}_{\mathrm{T}} \sin \left(\sigma-\varphi_{\mathrm{T}}\right) \cos \theta_{\mathrm{T}} \hat{\mathrm{n}}_{3}$

Substituting $\mathrm{Eq}^{\mathrm{ns}}(5,6)$ into (3) and comparing the individual components yield the scalar kinematic equations of missile c.g. motion as follows:

$$
\begin{array}{lll}
\dot{\mathrm{D}} & =\mathrm{V}_{\mathrm{T}} \cos \left(\sigma-\varphi_{\mathrm{T}}\right) \cos \left(\varepsilon-\theta_{\mathrm{T}}\right) & -\mathrm{V}_{\mathrm{M}} \cos \left(\sigma-\varphi_{\mathrm{M}}\right) \cos \left(\varepsilon-\theta_{\mathrm{M}}\right) \\
\mathrm{D} \dot{\varepsilon} & =\mathrm{V}_{\mathrm{M}} \cos \left(\sigma-\varphi_{\mathrm{M}}\right) \sin \left(\varepsilon-\theta_{\mathrm{M}}\right) & -\mathrm{V}_{\mathrm{T}} \cos \left(\sigma-\varphi_{\mathrm{T}}\right) \sin \left(\varepsilon-\theta_{\mathrm{T}}\right) \\
\mathrm{D} \cos \varepsilon \dot{\sigma} & =\mathrm{V}_{\mathrm{M}} \sin \left(\sigma-\varphi_{\mathrm{M}}\right) \cos \theta_{\mathrm{M}} & -\mathrm{V}_{\mathrm{T}} \sin \left(\sigma-\varphi_{\mathrm{T}}\right) \cos \theta_{\mathrm{T}}
\end{array}
$$

Alternatively, the left side of $\mathrm{Eq}^{\mathrm{n}}$ (3) can be projected along the reference directions by starting the projection on the horizontal plane then to the reference axes due to which the kinematic equations of missile c.g. motion are: 


$$
\begin{aligned}
\dot{\mathrm{D}}= & \mathrm{V}_{\mathrm{T}}\left\{\cos \theta_{\mathrm{T}} \cos \left(\sigma-\varphi_{\mathrm{T}}\right) \cos \varepsilon+\sin \theta_{\mathrm{T}} \sin \varepsilon\right\} \\
& -\mathrm{V}_{\mathrm{M}}\left\{\cos \theta_{\mathrm{M}} \cos \left(\sigma-\varphi_{\mathrm{M}}\right) \cos \varepsilon+\sin \theta_{\mathrm{M}} \sin \varepsilon\right\} \\
\mathrm{D} \dot{\varepsilon}= & \mathrm{V}_{\mathrm{M}}\left\{\cos \theta_{\mathrm{M}} \cos \left(\sigma-\varphi_{\mathrm{M}}\right) \sin \varepsilon-\sin \theta_{\mathrm{M}} \cos \varepsilon\right\} \\
& -\mathrm{V}_{\mathrm{T}}\left\{\cos \theta_{\mathrm{T}} \cos \left(\sigma-\varphi_{\mathrm{T}}\right) \sin \varepsilon-\sin \theta_{\mathrm{T}} \cos \varepsilon\right\} \\
\mathrm{D} \cos \varepsilon \dot{\sigma}= & \mathrm{V}_{\mathrm{M}} \cos \theta_{\mathrm{M}} \sin \left(\sigma-\varphi_{\mathrm{M}}\right)-\mathrm{V}_{\mathrm{T}} \cos \theta_{\mathrm{T}} \sin \left(\sigma-\varphi_{\mathrm{T}}\right)
\end{aligned}
$$

Another approach can be tackled to transform the velocity from its frame into the <xyz $>$ frame, and then from the $<x y z>$-axes into the D-frame which result in the kinematic equations of missile c.g. motion as:

$$
\begin{array}{lcc}
\dot{\mathrm{D}}= & \mathrm{V}_{\mathrm{T}}\left\{\mathrm{C} \varphi_{\mathrm{T}} \mathrm{C} \theta_{\mathrm{T}} \mathrm{C} \sigma \mathrm{C} \varepsilon+\mathrm{S} \theta_{\mathrm{T}} \mathrm{S} \varepsilon+\mathrm{S} \varphi_{\mathrm{T}} \mathrm{C} \theta_{\mathrm{T}} \mathrm{S} \sigma \mathrm{C} \varepsilon\right\} \\
& \quad-\mathrm{V}_{\mathrm{M}}\left\{\mathrm{C} \varphi_{\mathrm{m}} \mathrm{C} \theta_{\mathrm{m}} \mathrm{C} \sigma \mathrm{C} \varepsilon+\mathrm{S} \theta_{\mathrm{m}} \mathrm{S} \varepsilon+\mathrm{S} \varphi_{\mathrm{m}} \mathrm{C} \theta_{\mathrm{m}} \mathrm{S} \sigma \mathrm{C} \varepsilon\right\} \\
\mathrm{D} \dot{\varepsilon}= & \mathrm{V}_{\mathrm{M}}\left\{\mathrm{C} \varphi_{\mathrm{m}} \mathrm{C} \theta_{\mathrm{m}} \mathrm{C} \sigma \mathrm{S} \varepsilon-\mathrm{S} \theta_{\mathrm{m}} \mathrm{C} \varepsilon+\mathrm{S} \varphi_{\mathrm{m}} \mathrm{C} \theta_{\mathrm{m}} \mathrm{S} \sigma \mathrm{S} \varepsilon\right\} \\
\quad-\mathrm{V}_{\mathrm{T}}\left\{\mathrm{C} \varphi_{\mathrm{T}} \mathrm{C} \theta_{\mathrm{T}} \mathrm{C} \sigma \mathrm{S} \varepsilon-\mathrm{S} \theta_{\mathrm{T}} \mathrm{C} \varepsilon+\mathrm{S} \varphi_{\mathrm{T}} \mathrm{C} \theta_{\mathrm{T}} \mathrm{S} \sigma \mathrm{S} \varepsilon\right\} \\
\mathrm{D} \cos \varepsilon \dot{\sigma}= & \mathrm{V}_{\mathrm{M}}\left\{\mathrm{C} \varphi_{\mathrm{m}} \mathrm{C} \theta_{\mathrm{m}} \mathrm{S} \sigma-\mathrm{S} \varphi_{\mathrm{m}} \mathrm{C} \theta_{\mathrm{m}} \mathrm{C} \sigma\right\}-\mathrm{V}_{\mathrm{T}}\left\{\mathrm{C} \varphi_{\mathrm{T}} \mathrm{C} \theta_{\mathrm{T}} \mathrm{S} \sigma-\mathrm{S} \varphi_{\mathrm{T}} \mathrm{C} \theta_{\mathrm{T}} \mathrm{C} \sigma\right\}
\end{array}
$$

\subsection{Basic Guidance Methods}

The ideal bond (IB) (law of guidance) equations are dependent upon the method of guidance used to guide the missile for intercepting its designated target.

\subsubsection{IB Imposed upon $\hat{X}_{1}$}

This guidance method limits the direction of $\hat{\mathrm{X}}_{1}$ where the relative position between $\hat{\mathrm{X}}_{1}$ and $\overline{\mathrm{D}}$ is considered and consequently there exist four cases: either $\varepsilon_{\mathrm{P}}=0, \varepsilon_{\mathrm{P}}=$ constant, $\varepsilon_{\mathrm{P}}=\mathrm{f}\left(\bar{\omega}_{\overline{\mathrm{D}}}\right)=\Delta_{\mathrm{O}}+\tau \dot{\varepsilon}$, or $\varepsilon_{\mathrm{P}}=\mathrm{f}\left(\theta_{\mathrm{o}}\right)$, where $\Delta_{O}$ and $\tau$ are constants.

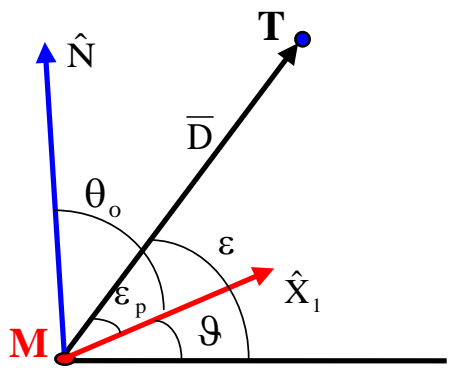

Fig. 2a $X_{1}$-Imposed Geometry

\subsubsection{IB Imposed upon $\bar{D}$}

The most known guidance method is the constant bearing or parallel approach in which the direction of $\overline{\mathrm{D}}$ does not change. That is, the angular velocity of the LOS $\overline{\mathrm{D}}$ is kept zero during missile flight until target interception; $\dot{\varepsilon}=0$ and $\dot{\sigma}=0$ or $\varepsilon=\varepsilon_{\mathrm{P}}$ and $\sigma=\sigma_{\mathrm{P}}$, where $\varepsilon_{\mathrm{p}}$ and $\sigma_{\mathrm{p}}$ are constants.

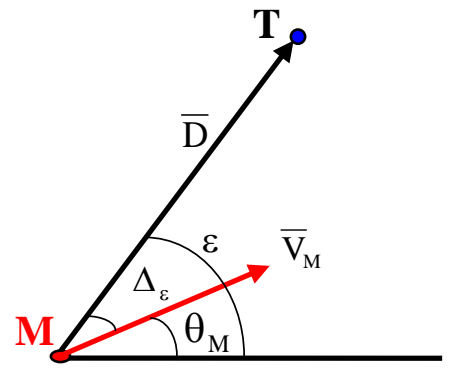

Fig. 2b: VM-Imposed Geometry

\subsubsection{IB Imposed upon $\bar{V}_{M}$}

This method of guidance limits the direction of vector $\bar{V}_{\mathrm{M}}$ due to which there are three methods as follows:

1. Pure-pursuit guidance method where $\bar{V}_{\mathrm{M}}$ is always directed towards the targets i.e. $\Delta_{\varepsilon}=0$ i.e. $\theta_{\mathrm{M}}=\varepsilon$.

$$
\theta_{M}=\varepsilon \quad \& \quad \varphi_{M}=\sigma
$$


2. Deviated-pursuit guidance method where $\Delta_{\varepsilon}=$ constant .

\begin{tabular}{|l|l|l|}
\hline$\theta_{\mathrm{M}}=\varepsilon-\varepsilon_{\mathrm{p}} \quad \& \quad \varphi_{\mathrm{M}}=\sigma-\sigma_{\mathrm{p}}$ & (9) \\
\hline
\end{tabular}

where $\varepsilon_{\mathrm{p}}$ and $\beta_{\mathrm{p}}$ are constants.

3. Proportional-Navigation guidance method where $\Delta_{\varepsilon}=\mathrm{f}\left(\bar{\omega}_{\overline{\mathrm{D}}}\right)$.

$$
\dot{\theta}_{\mathrm{M}}=\mathrm{k}_{1} \dot{\varepsilon} \quad \& \quad \dot{\varphi}_{\mathrm{M}}=\mathrm{k}_{2} \dot{\sigma}
$$

where $\mathrm{K}_{1}$ and $\mathrm{K}_{2}$ are the navigation constants.

\subsection{Nature of Derived Guidance Equations}

Clearly we have 5-equations $\{3$ scalar kinematic equations and two ideal bonds with 6unknowns $\left\{\mathrm{D}, \varepsilon, \sigma, \mathrm{V}_{\mathrm{M}}, \theta_{\mathrm{M}}, \varphi_{\mathrm{M}}\right\}$. Thus, the motion of a guided missile is not defined only by kinematic coupling, but the actual motion of a rigid body is given by forces acting upon it. Considering the effect of these forces, the missile's velocity $V_{M}$ can be considered a known function of time and the system of equations become closed (6-equations in 6- unknowns). The solution of this set of equations yields the missile kinematic trajectory in addition to the time of flight, the demanded turning rate, the normal acceleration, the miss distance, the launching angular directions, the directions of approaching the target at intercept, ...etc.

These kinematic differential equations can be solved either analytically or numerically. The numerical solution can be carried out utilizing one of the known numerical integration methods such as Euler's, Runge Kutta, Predictor Corrector, Adam's Basheforth, Gear's methods on PCs. While, the analytic solution is difficult and complex for spatial motion and therefore it can carried only for simplified engagement scenarios such as planner motion in either the vertical or horizontal plane, constant altitude of target flight and constant speeds for both target and missile. That is, planner motion will lead to simplified kinematic equations and ideal bonds that could be algebraically manipulated then integrated to yield an analytic form for the LOS distance $\mathrm{D}=\mathrm{f}(\varepsilon), \mathrm{t}=\mathrm{f}(\mathrm{D}, \varepsilon), \mathrm{J}_{\mathrm{N}}=\mathrm{f}(\mathrm{D}, \varepsilon)$, the miss distance and the time of flight.

Generally, the solution of the 5-equations yields the unknowns ( $\left.D, \varepsilon, \sigma, \theta_{M}, \varphi_{M}\right)$ as functions of time, since the kinematic parameters of target motion are known functions of time. Consequently, the kinematic investigation of missile motion helps to determine the shape of trajectories and the necessary maneuver the missile has to execute to intercept the designated target under the assumption of known missile velocity.

\section{Missile Normal Acceleration}

For intercepting or engaging a target there are some requirements imposed upon the guided missile including its capability to maneuver. This maneuver is accomplished by producing acceleration normal to the velocity vector resulting in an attitude maneuver. Therefore, acceleration is one of the most important system parameters and because of practical limitations (admissible missile capabilities) it is one of the major constraints in accomplishing an intercept.

A guided missile can fly along a curve with only a certain minimum radius of curvature. Due to which there is centripetal force must acting on it. However, airframe as well as the board equipment does not sustain arbitrary centripetal force proportional to which is the normal acceleration. Let the missile should be subject to excessive normal acceleration, the maximum deflection of controls is limited in dependence upon the dynamic pressure so that the 
maximum admissible normal acceleration should not exceeded. Solving the kinematic path of a guided missile yields simultaneously the missile normal acceleration. Therefore, it is possible to determine areas in the space where the guided missile can be guided by a certain guidance method without exceeding the maximum permissible normal acceleration.

The more curved is the target maneuver the greater dynamic errors are originating. Therefore, we shall find such methods of guidance in which the normal acceleration of the missile will be as small as possible. Also, we had to know the needed and possible normal accelerations of the missile for its guidance. The determination of normal acceleration of a missile for a given method of guidance as a function of range (D), elevation angle $(\varepsilon)$ and azimuth angle $(\sigma)$ is presented in the following subsections. It is necessary to know the values of normal acceleration the missile has to survive or execute without some substantial damage. Therefore, the ideal trajectory of a missile flight to intercept a designated target should be expressed and the variation of missile velocity $\bar{V}_{M}$ is determined to yield the kinematic normal acceleration of interest. The kinematic normal acceleration is a geometrical variable characterizing the curvature of a missile ideal flight path in a given time. According to Fig. 3, the acceleration to be executed by the missile is given as follows:

$$
\overline{\mathrm{J}}=\frac{\mathrm{d}\left\{\mathrm{V}_{\mathrm{M}} \hat{\mathrm{V}}_{\mathrm{M}}\right\}}{\mathrm{dt}}=\dot{\mathrm{V}}_{\mathrm{M}} \hat{\mathrm{V}}_{\mathrm{M}}+\bar{\omega}_{\mathrm{V}_{\mathrm{M}}} \otimes \overline{\mathrm{V}}_{\mathrm{M}}=\overline{\mathrm{J}}_{\mathrm{t}}+\overline{\mathrm{J}}_{\mathrm{N}}
$$

where $\bar{\omega}_{V_{M}}$ is the lateral rate of change of missile velocity vector $\overline{\mathrm{V}}_{\mathrm{M}}$ w.r.t. time (turning rate) and therefore it is given by $\bar{\omega}_{\mathrm{V}_{\mathrm{M}}}=\dot{\bar{\theta}}_{\mathrm{M}}+\dot{\bar{\varphi}}_{\mathrm{M}}$ with the following components

$$
\bar{\omega}_{V_{M}}=-\dot{\varphi}_{M} \sin \theta_{M} \hat{i}-\dot{\varphi}_{M} \cos \theta_{M} \hat{j}+\dot{\theta}_{M} \hat{k}
$$

The normal acceleration $\bar{J}_{\mathrm{N}}$ for spatial motion of missile is given by

$$
\bar{J}_{N}=\bar{\omega}_{V_{M}} \otimes \bar{V}_{M}=V_{M} \dot{\theta}_{M} \hat{j}+V_{M} \dot{\varphi}_{M} \cos \theta_{M} \hat{k}
$$

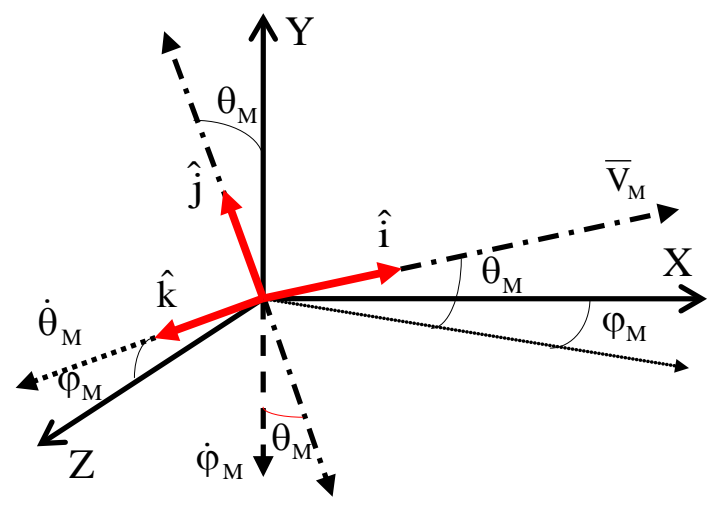

Fig. 3a Geometry of turning rates

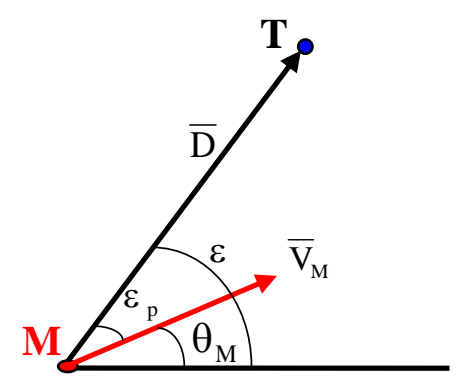

Fig. 3b VM-Imposed geometry

\subsection{Ideal-Bond Imposed upon $\overline{\mathrm{V}}_{\mathrm{M}}$}

In this case the ideal bond, assuming vertical plane motion, Fig. 3b, has the form

$$
\varepsilon-\theta_{\mathrm{M}}=\varepsilon_{\mathrm{p}} \Rightarrow \dot{\theta}_{\mathrm{M}}=\dot{\varepsilon}-\dot{\varepsilon}_{\mathrm{p}}
$$

The missile normal acceleration is given by

$$
\mathrm{J}_{\mathrm{N}}=\mathrm{V}_{\mathrm{M}} \dot{\varepsilon}-\mathrm{V}_{\mathrm{M}} \dot{\varepsilon}_{\mathrm{p}}
$$

Since $\varepsilon_{\mathrm{p}}=\mathrm{f}\left(\mathrm{t}, \mathrm{D}, \varepsilon, \theta_{\mathrm{M}}\right)$ its rate of change is given in the following form

$$
\dot{\varepsilon}_{\mathrm{p}}=\frac{\partial \varepsilon_{\mathrm{p}}}{\partial \mathrm{t}}+\frac{\partial \varepsilon_{\mathrm{p}}}{\partial \mathrm{D}} \dot{\mathrm{D}}+\frac{\partial \varepsilon_{\mathrm{p}}}{\partial \varepsilon} \dot{\varepsilon}+\frac{\partial \varepsilon_{\mathrm{p}}}{\partial \theta_{\mathrm{M}}} \dot{\theta}_{\mathrm{M}}
$$

From the kinematic equations (7) of missile c.g. motion $\dot{\varepsilon}$ can be obtained as follows: 


$$
\dot{\varepsilon}=\frac{1}{\mathrm{D}}\left\{\mathrm{V}_{\mathrm{M}} \sin \left(\varepsilon-\theta_{\mathrm{M}}\right)-\mathrm{V}_{\mathrm{T}} \sin \left(\varepsilon-\theta_{\mathrm{T}}\right)\right\}
$$

Using $\mathrm{Eq}^{\mathrm{ns}}(16,17)$, the missile normal acceleration can be obtained as:

$$
\mathrm{J}_{\mathrm{N}}=\frac{\mathrm{V}_{\mathrm{M}}}{1+\frac{\partial \varepsilon_{\mathrm{p}}}{\partial \theta_{\mathrm{M}}}}\left\{\mathrm{A}_{2}\left[1-\frac{\partial \varepsilon_{\mathrm{p}}}{\partial \varepsilon}\right]-\mathrm{A}_{1} \frac{\partial \varepsilon_{\mathrm{p}}}{\partial \mathrm{D}}-\frac{\partial \varepsilon_{\mathrm{p}}}{\partial \mathrm{t}}\right\}
$$

$$
\text { where } \quad \mathrm{A}_{1}=\mathrm{V}_{\mathrm{T}} \cos \left(\varepsilon-\theta_{\mathrm{T}}\right)-\mathrm{V}_{\mathrm{M}} \cos \varepsilon_{\mathrm{p}} \quad \& \quad \mathrm{~A}_{2} \frac{1}{\mathrm{D}}\left\{\mathrm{V}_{\mathrm{M}} \sin \varepsilon_{\mathrm{p}}-\mathrm{V}_{\mathrm{T}} \sin \left(\varepsilon-\theta_{\mathrm{T}}\right)\right\}
$$

Once the form of ideal bond is given (the function $\varepsilon_{\mathrm{p}}$ ), the demanded normal acceleration can be obtained and then analyzed.

\subsection{Ideal-Bond Imposed upon $\bar{D}$}

For planar motion in the vertical plane, the missile normal acceleration is the multiplication of missile velocity and the turning rate in this plane. Therefore, the objective of this section is to try finding a relationship for the angle $\theta_{\mathrm{M}}$ and other

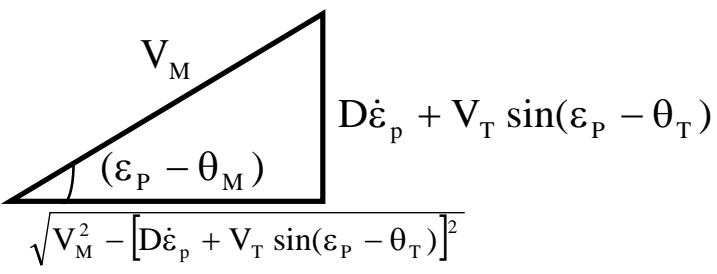
motion parameters. The kinematic equations of missile motion in vertical plane are obtained from $\mathrm{Eq}^{\text {ns }}(7)$. The ideal bond equation is given by

$$
\varepsilon=\varepsilon_{\mathrm{P}}
$$

Substituting $\mathrm{Eq}^{\mathrm{n}}$ (19) into (7) and considering vertical plane motion yield

$$
\begin{aligned}
& \mathrm{D} \dot{\varepsilon}_{\mathrm{p}}+\mathrm{V}_{\mathrm{T}} \sin \left(\varepsilon_{\mathrm{P}}-\theta_{\mathrm{T}}\right)=\mathrm{V}_{\mathrm{M}} \sin \left(\varepsilon_{\mathrm{P}}-\theta_{\mathrm{M}}\right) \\
& \Rightarrow \cos \left(\varepsilon_{\mathrm{P}}-\theta_{\mathrm{M}}\right)=\frac{1}{\mathrm{~V}_{\mathrm{M}}} \sqrt{\mathrm{V}_{\mathrm{M}}^{2}-\left[\mathrm{D} \dot{\varepsilon}_{\mathrm{p}}+\mathrm{V}_{\mathrm{T}} \sin \left(\varepsilon_{\mathrm{P}}-\theta_{\mathrm{T}}\right)\right]^{2}}
\end{aligned}
$$

Since $\mathrm{J}_{\mathrm{N}}=\mathrm{V}_{\mathrm{M}} \dot{\theta}_{\mathrm{M}}$, we are going to differentiate $\mathrm{Eq}^{\mathrm{n}}$ (21a) to obtain $\dot{\theta}_{\mathrm{M}}$ as follows:

$$
\begin{aligned}
\dot{\mathrm{D}} \dot{\varepsilon}_{\mathrm{P}}+\mathrm{D} \ddot{\varepsilon}_{\mathrm{P}}+\dot{\mathrm{V}}_{\mathrm{T}} \sin \left(\varepsilon_{\mathrm{P}}-\theta_{\mathrm{T}}\right)+\mathrm{V}_{\mathrm{T}} \cos \left(\varepsilon_{\mathrm{P}}-\theta_{\mathrm{T}}\right)\left(\dot{\varepsilon}_{\mathrm{P}}-\dot{\theta}_{\mathrm{T}}\right)= \\
\dot{\mathrm{V}}_{\mathrm{M}} \sin \left(\varepsilon_{\mathrm{P}}-\theta_{\mathrm{M}}\right)+\mathrm{V}_{\mathrm{M}} \cos \left(\varepsilon_{\mathrm{P}}-\theta_{\mathrm{M}}\right)\left(\dot{\varepsilon}_{\mathrm{P}}-\dot{\theta}_{\mathrm{M}}\right)
\end{aligned}
$$

Considering $\mathrm{Eq}^{\mathrm{ns}}$ (7) and eliminating the unknowns in the resulting denominators yield the following form of the missile normal acceleration:

$$
\begin{array}{r}
\mathrm{J}_{\mathrm{N}_{\mathrm{M}}}=2 \mathrm{~V}_{\mathrm{M}} \dot{\varepsilon}_{\mathrm{P}}+\frac{\mathrm{J}_{\mathrm{N}_{\mathrm{T}}} \mathrm{V}_{\mathrm{M}} \cos \left(\varepsilon_{\mathrm{P}}-\theta_{\mathrm{T}}\right)+\mathrm{V}_{\mathrm{T}}^{2} \dot{\mathrm{P}} \sin \left(\varepsilon_{\mathrm{P}}-\theta_{\mathrm{T}}\right)}{\sqrt{\mathrm{V}_{\mathrm{M}}^{2}-\left[\mathrm{D} \dot{\varepsilon}_{\mathrm{P}}+\mathrm{V}_{\mathrm{T}} \sin \left(\varepsilon_{\mathrm{P}}-\theta_{\mathrm{T}}\right)\right]^{2}}} \\
+\frac{\mathrm{D}\left(\dot{\mathrm{V}}_{\mathrm{M}} \dot{\varepsilon}_{\mathrm{P}}-\mathrm{V}_{\mathrm{M}} \ddot{\varepsilon}_{\mathrm{P}}\right)-2 \mathrm{~V}_{\mathrm{T}} \mathrm{V}_{\mathrm{M}} \dot{\varepsilon}_{\mathrm{P}} \cos \left(\varepsilon_{\mathrm{P}}-\theta_{\mathrm{T}}\right)}{\sqrt{\mathrm{V}_{\mathrm{M}}^{2}-\left[\mathrm{D} \dot{\varepsilon}_{\mathrm{P}}+\mathrm{V}_{\mathrm{T}} \sin \left(\varepsilon_{\mathrm{P}}-\theta_{\mathrm{T}}\right)\right]^{2}}}
\end{array}
$$

where; $\mathrm{P}=\mathrm{V}_{\mathrm{M}} / \mathrm{V}_{\mathrm{T}}$ from which it is clear that

$$
\begin{aligned}
& \dot{\mathrm{P}}=\frac{\mathrm{d}}{\mathrm{dt}}\left(\frac{\mathrm{V}_{\mathrm{M}}}{\mathrm{V}_{\mathrm{T}}}\right)=\frac{\dot{\mathrm{V}}_{\mathrm{M}} \mathrm{V}_{\mathrm{T}}-\mathrm{V}_{\mathrm{M}} \dot{\mathrm{V}}_{\mathrm{T}}}{\mathrm{V}_{\mathrm{T}}^{2}} \\
& \mathrm{~J}_{\mathrm{N}_{\mathrm{T}}}=\mathrm{V}_{\mathrm{T}} \dot{\theta}_{\mathrm{T}}
\end{aligned}
$$

For the constant bearing guidance method, the law of ideal bond equation has the form $\varepsilon_{\mathrm{P}}=$ constant or $\dot{\varepsilon}=\dot{\varepsilon}_{\mathrm{P}}=0$. Thus, equation (22) can be simplified as follows: 


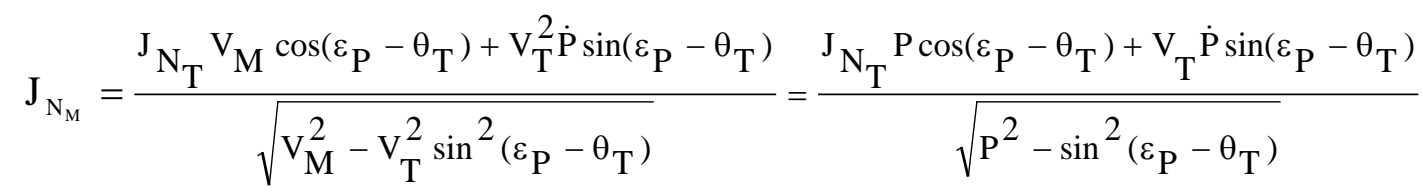

It is clear that

$$
\left[\mathrm{P}^{2}-\sin ^{2}\left(\varepsilon_{\mathrm{P}}-\theta_{\mathrm{T}}\right)\right]>0 \quad \stackrel{!}{!} \quad \Rightarrow \mathrm{P}^{2}>\sin ^{2}\left(\varepsilon_{\mathrm{P}}-\theta_{\mathrm{T}}\right) \quad \Rightarrow \mathrm{P}^{2}>1
$$

This result leads to the following equality

$$
\mathrm{P}\left|\cos \left(\varepsilon_{\mathrm{P}}-\theta_{\mathrm{T}}\right)\right|=\sqrt{\mathrm{P}^{2} \cos ^{2}\left(\varepsilon_{\mathrm{P}}-\theta_{\mathrm{T}}\right)}=\sqrt{\mathrm{P}^{2}-\mathrm{P}^{2} \sin ^{2}\left(\varepsilon_{\mathrm{P}}-\theta_{\mathrm{T}}\right)} \leq \sqrt{\mathrm{P}^{2}-\sin ^{2}\left(\varepsilon_{\mathrm{P}}-\theta_{\mathrm{T}}\right)}
$$

Since

$$
\mathrm{J}_{\mathrm{M}}=\frac{\mathrm{P} \cos \left(\varepsilon_{\mathrm{P}}-\theta_{\mathrm{T}}\right)}{\sqrt{\mathrm{P}^{2}-\sin ^{2}\left(\varepsilon_{\mathrm{P}}-\theta_{\mathrm{T}}\right)}} \mathrm{J}_{\mathrm{T}}+\frac{\dot{\mathrm{P}} \sin \left(\varepsilon_{\mathrm{P}}-\theta_{\mathrm{T}}\right)}{\sqrt{\mathrm{P}^{2}-\sin ^{2}\left(\varepsilon_{\mathrm{P}}-\theta_{\mathrm{T}}\right)}} \mathrm{V}_{\mathrm{T}}
$$

Then, for $\mathrm{P}=$ constant and $\mathrm{P}>1$ we have $\dot{\mathrm{P}}=0$ and the missile normal acceleration $\left(\mathrm{J}_{\mathrm{N}_{\mathrm{M}}}\right)$ cannot be greater than the target normal acceleration $\left(\mathrm{J}_{\mathrm{N}_{\mathrm{T}}}\right)$ i.e. $\mathrm{J}_{\mathrm{N}_{\mathrm{T}}} \geq \mathrm{J}_{\mathrm{N}_{\mathrm{M}}}$. For the construction of the curve $\mathrm{J}_{\mathrm{N}_{\mathrm{M}}}=$ constant, it is necessary to solve Eq ${ }^{\text {ns }}$ (24) according to $\mathrm{D}$ for $\mathrm{J}_{\mathrm{N}_{\mathrm{M}}}=$ cons tan $\mathrm{t}$.

\section{Miss Distance}

The radial miss distance is the scalar distance separating the missile and target near the intercept point, while the vector of miss distance is a vector from the target to the missile at that instant. The miss distance calculation procedure is to first determine the time-to-go to the closest point of approach followed by the computation of the relative position of the missile to the target at that time. Generally, the miss distance can be expressed by the vector equation:

$$
\overline{\mathrm{D}}_{\text {miss }}=\overline{\mathrm{D}}+\dot{\overline{\mathrm{D}}} \cdot \mathrm{t}_{\mathrm{g}}
$$

where; $\overline{\mathrm{D}}$ the missile-target range vector i.e. $\left[\begin{array}{lll}x_{\mathrm{tm}} & \mathrm{y}_{\mathrm{tm}} & \mathrm{z}_{\mathrm{tm}}\end{array}\right]$, $\dot{\overline{\mathrm{D}}}$ the missile-target range rate vector, $t_{g}$ the time to go (the time to intercept the maneuvering target), $t$ the instantaneous time of flight, and $t_{f}$ the time of missile flight. The time to go is the time to intercept the maneuvering target and it is given by

$$
\mathrm{t}_{\mathrm{g}}=\mathrm{t}_{\mathrm{f}}-\mathrm{t}=\frac{\mathrm{D}}{\mathrm{D}}=\frac{\mathrm{D}}{\mathrm{V}_{\mathrm{c}}}=\frac{\mathrm{D}}{\mathrm{V}_{\mathrm{tm}}}
$$

where $\mathrm{V}_{\mathrm{c}}$ is the closing velocity and $\mathrm{V}_{\mathrm{tm}}$ is the relative velocity between missile and target velocities i.e. $V_{t m}=\left[V_{t_{\mathrm{x}}} V_{\mathrm{tm}_{\mathrm{y}}} \mathrm{V}_{\mathrm{tm}_{\mathrm{z}}}\right]$. To achieve a successful intercept the miss distance normal to the range vector should be driven to zero which can be expressed as follows:

$$
\overline{\mathrm{D}}_{\text {miss }}^{\perp}=\overline{\mathrm{D}}_{\text {miss }} \otimes \hat{\mathrm{D}}
$$

Then according to $\mathrm{Eq}^{\mathrm{n}}$ (28), the miss distance normal to the range is given as

$$
\overline{\mathrm{D}}_{\text {miss }}^{\perp}=\overline{\mathrm{D}} \otimes \hat{\mathrm{D}}+\mathrm{t}_{\mathrm{g}} \dot{\overline{\mathrm{D}}} \otimes \hat{\mathrm{D}}
$$

Differentiating the range equation gives

$$
\dot{\overline{\mathrm{D}}} \equiv \frac{\mathrm{d} \overline{\mathrm{D}}}{\mathrm{dt}}=\dot{\mathrm{D}} \hat{\mathrm{D}}+\mathrm{D} \bar{\omega}_{\overline{\mathrm{D}}} \otimes \hat{\mathrm{D}}
$$

where $\bar{\omega}_{\overline{\mathrm{D}}}$ is the line-of-sight rate. Then, substituting $\mathrm{Eq}^{\mathrm{n}}$ (31) into $\mathrm{Eq}^{\mathrm{n}}$ (30) yields

$$
\overline{\mathrm{D}}_{\text {miss }}^{\perp}=\overline{\mathrm{D}} \otimes \hat{\mathrm{D}}+\mathrm{t}_{\mathrm{g}} \dot{\mathrm{D}}(\hat{\mathrm{D}} \otimes \hat{\mathrm{D}})+\mathrm{t}_{\mathrm{g}} \mathrm{D}\left(\bar{\omega}_{\overline{\mathrm{D}}} \otimes \hat{\mathrm{D}}\right) \otimes \hat{\mathrm{D}}
$$

Since $\overline{\mathrm{D}} \otimes \hat{\mathrm{D}}$ and $\hat{\mathrm{D}} \otimes \hat{\mathrm{D}}$ are equal to zero, the above equation is simplified to the following: 


$$
\overline{\mathrm{D}}_{\text {miss }}^{\perp}=\mathrm{t}_{\mathrm{g}} \mathrm{D} \bar{\omega}_{\overline{\mathrm{D}}}^{\perp}=\mathrm{t}_{\mathrm{g}} \mathrm{D}\left\{\bar{\omega}_{\overline{\mathrm{D}}}^{\perp}=\bar{\omega}_{\overline{\mathrm{D}}} \otimes \hat{\mathrm{D}}_{\varepsilon}+\bar{\omega}_{\overline{\mathrm{D}}} \otimes \hat{\mathrm{D}}_{\sigma}\right\}
$$

where $\bar{\omega}_{\overline{\mathrm{D}}}^{\perp}$ is the component of $\bar{\omega}_{\overline{\mathrm{D}}}$ and normal to the line-of-sight. The normal components are obtained as follows:

$$
\bar{\omega}_{\overline{\mathrm{D}}} \otimes \hat{\mathrm{D}}_{\varepsilon}=-\dot{\varepsilon} \hat{\mathrm{x}}_{\mathrm{o}}+\dot{\sigma} \sin \varepsilon \hat{\mathrm{z}}_{\mathrm{o}} \quad \& \quad \bar{\omega}_{\overline{\mathrm{D}}} \otimes \hat{\mathrm{D}}_{\sigma}=\dot{\sigma} \cos \varepsilon \hat{\mathrm{x}}_{\mathrm{o}}-\dot{\sigma} \sin \varepsilon \hat{\mathrm{y}}_{\mathrm{o}}
$$

Therefore, the normal component of angular velocity $\bar{\omega}_{\overline{\mathrm{D}}}^{\perp}$ is obtained and substituted into $\mathrm{Eq}^{\mathrm{n}}(33)$ to yield the lateral-miss distance as follows:

$$
\begin{aligned}
& \bar{\omega}_{\overline{\mathrm{D}}}^{\perp}=\bar{\omega}_{\overline{\mathrm{D}}} \otimes \hat{\mathrm{D}}_{\varepsilon}+\bar{\omega}_{\overline{\mathrm{D}}} \otimes \hat{\mathrm{D}}_{\sigma}=(\dot{\sigma} \cos \varepsilon-\dot{\varepsilon}) \hat{\mathrm{x}}_{\mathrm{o}}-(\dot{\sigma} \sin \varepsilon) \hat{\mathrm{y}}_{\mathrm{o}}+(\dot{\sigma} \sin \varepsilon) \hat{\mathrm{z}}_{\mathrm{o}} \\
& \rightarrow \quad \overline{\mathrm{D}}_{\text {miss }}^{\perp}=\mathrm{t}_{\mathrm{g}} \mathrm{D}\left[(\dot{\sigma} \cos \varepsilon-\dot{\varepsilon}) \hat{\mathrm{x}}_{\mathrm{o}}-(\dot{\sigma} \sin \varepsilon) \hat{\mathrm{y}}_{\mathrm{o}}+(\dot{\sigma} \sin \varepsilon) \hat{\mathrm{z}}_{\mathrm{o}}\right]
\end{aligned}
$$

Therefore, the components of the miss distance vector are given by $\mathrm{x}_{\text {miss }}=\mathrm{t}_{\mathrm{g}} \mathrm{D}(\dot{\sigma} \cos \varepsilon-\dot{\varepsilon})$, $\mathrm{y}_{\text {miss }}=-\mathrm{t}_{\mathrm{g}} \mathrm{D}(\dot{\sigma} \sin \varepsilon)$, and $\mathrm{z}_{\text {miss }}=\mathrm{t}_{\mathrm{g}} \mathrm{D}(\dot{\sigma} \sin \varepsilon)$. That is, the magnitude of the miss distance vector are given by $D_{\text {miss }}^{\perp}=\sqrt{x_{\text {miss }}^{2}+y_{\text {miss }}^{2}+z_{\text {miss }}^{2}}$. Thus, the angular velocity $\bar{\omega}_{\overline{\mathrm{D}}}^{\perp}$ should be zero to yield zero normal miss distance when $t_{g}>0$. Consequently, if the LOS rate can be measured in the missile and used as a basis for steering commands, the missile will be guided to a successful intercept. This is the idea of proportional navigation guidance method used with either homing or command guided missiles. The relative flight parameters can be utilized to estimate the miss distance by obtaining firstly the time to go using the definition in $\mathrm{Eq}^{\mathrm{n}}$ (28b) as follows:

$$
\mathrm{t}_{\mathrm{g}}=\frac{\overline{\mathrm{D}} \cdot \overline{\mathrm{V}}_{\mathrm{tm}}}{\overline{\mathrm{V}}_{\mathrm{tm}} \cdot \overline{\mathrm{V}}_{\mathrm{tm}}}=\frac{\mathrm{x}_{\mathrm{tm}_{\mathrm{m}}} \mathrm{V}_{\mathrm{tm}_{\mathrm{x}}}+\mathrm{y}_{\mathrm{tm}_{\mathrm{tm}}}+\mathrm{V}_{\mathrm{tm}_{\mathrm{tm}}} \mathrm{V}_{\mathrm{tm}_{\mathrm{z}}}}{\mathrm{V}_{\mathrm{tm}}^{2}}
$$

where; the relative position and velocity components between missile and target are given by

$$
\begin{array}{lll}
\mathrm{x}_{\mathrm{tm}}=\mathrm{x}_{\mathrm{t}}-\mathrm{x}_{\mathrm{m}} & \mathrm{V}_{\mathrm{tm}_{\mathrm{x}}}=\mathrm{V}_{\mathrm{m}_{\mathrm{x}}}-\mathrm{V}_{\mathrm{t}_{\mathrm{x}}} \\
\mathrm{y}_{\mathrm{tm}}=\mathrm{y}_{\mathrm{t}}-\mathrm{y}_{\mathrm{m}} & \& \mathrm{~V}_{\mathrm{tm}_{\mathrm{y}}}=\mathrm{V}_{\mathrm{m}_{\mathrm{y}}}-\mathrm{V}_{\mathrm{t}_{\mathrm{y}}} \\
\mathrm{z}_{\mathrm{tm}}=\mathrm{z}_{\mathrm{t}}-\mathrm{z}_{\mathrm{m}} & \mathrm{V}_{\mathrm{tm}_{\mathrm{z}}}=\mathrm{V}_{\mathrm{m}_{\mathrm{z}}}-\mathrm{V}_{\mathrm{t}_{\mathrm{z}}}
\end{array}
$$

Then, the total relative velocity between missile and target is given as follows:

$$
\mathrm{V}_{\mathrm{tm}}=\sqrt{\mathrm{V}_{\mathrm{tm}_{\mathrm{x}}}^{2}+\mathrm{V}_{\mathrm{tm}_{\mathrm{y}}}^{2}+\mathrm{V}_{\mathrm{tm}_{\mathrm{z}}}^{2}}
$$

The alternative approach to calculate the components of the miss-distance directly using $\mathrm{Eq}^{\text {ns }}$ (35) can be carried out according to the following relations:

$$
\begin{aligned}
& \mathrm{x}_{\text {miss }}=\mathrm{x}_{\mathrm{tm}}+\mathrm{V}_{\mathrm{tm}_{\mathrm{x}}} \mathrm{t}_{\mathrm{g}} \\
& \mathrm{y}_{\text {miss }}=\mathrm{y}_{\mathrm{tm}}+\mathrm{V}_{\mathrm{tm}_{\mathrm{y}}} \mathrm{t}_{\mathrm{g}} \\
& \mathrm{z}_{\text {miss }}=\mathrm{z}_{\mathrm{tm}}+\mathrm{V}_{\mathrm{tm}_{\mathrm{z}}} \mathrm{t}_{\mathrm{g}}
\end{aligned}
$$

Therefore, the total miss distance is given by $\mathrm{D}_{\text {miss }}=\sqrt{\mathrm{x}_{\text {miss }}^{2}+\mathrm{y}_{\text {miss }}^{2}+\mathrm{z}_{\text {miss }}^{2}}$. The projected closest point of approach can be determined at each step of simulation, based on the instantaneous position and velocity components of missile and target. Consequently, a plot of this projection indicates the progression of the missile toward a successful interception with the target. In addition, it provides a graphic indication of the effect of perturbations on the guidance process. 


\section{Flight Path Characteristics}

The trajectory or flight path is obtained by solving the equations of c.g. motion in conjunction with ideal bond equations either numerically or analytically. The analytical solution can be very complex unless some simplifying assumptions are considered such as planer motion, constant speeds, etc. The guidance performance is analyzed via flight path parameters obtained from the equations solution. The main features of the guidance system design can be summarized as follows:

- The trajectory itself,

- Time of flight from which the computer/processor parameters are determined as well as the tactical requirements,

- The maximum rate of turn and the maximum lateral acceleration are utilized to determine the proper type of guidance, which could be employed for a given tactical situation. In addition, these factors are important in the design of missile airframe and control devices,

- The frequency demand required for guidance and control which is important for the control servos and associated network, and

- The miss distance.

The missile engineer should have a broader view, and hence a better appreciation of the various designs aspects in order to achieve a more efficient design. The design of missile configurations is one of the most interesting and challenging fields and most complex for the aeronautical design engineer. It requires a reasonably broad knowledge of the fundamentals of many technical specialties or disciplines: aerodynamics, thermodynamics, kinematics, propulsion, structural design, analogue and digital/logic circuits, computers, applied and advanced mathematics, etc. The missile configuration culminates from many design compromises to achieve a final system that meets the over-all weapon requirements. The optimization of design is gained by careful analysis of the following considerations:

- Simplicity in external configuration to reduce development time and cost, range, speed and other performance characteristics that satisfy the mission requirements

- Efficient aerodynamic control surfaces to simplify control and guidance system circuits and to minimize servo power requirements

- Adequacy of the airframe from the stability, maneuverability and dynamic responses view points.

- Simple, efficient and highly reliable power plant.

- Low cost, producability, and lightweight airframe construction.

- Accuracy of the control and guidance systems to accomplish the desired mission

- Reliability of the complete weapon system as well as its individual components

- Efficiency in packaging the various major components to facilitate checkout and replacement.

The guided missile follows a prescribed or designed flight path or trajectory which could be one of the following: Straight line trajectory, LOS trajectory, Boost/Boost glide trajectory, Boost sustain trajectory, Gravity glide trajectory, Sustain trajectory, Cruise trajectory, Ballistic (free fall) trajectory, and Proportional navigation trajectory.

\section{Flight Path Calculation}

This section is devoted to solve the derived equations of c.g. motion $\mathrm{Eq}^{\mathrm{ns}}$ (7) in conjunction with ideal bond equations (8-10) either numerically or analytically. Then, the guidance performance is analyzed via flight path parameters obtained from the equations solution. The 
obtained equations are programmed as functions within the MATLAB environment (or any high level language) and the simulation is conducted using different engagements' scenarios.

\subsection{Numerical Solution}

Considering the differential original $\mathrm{Eq}^{\mathrm{ns}}$ (7) in vertical plane, solving it numerically via the Euler's numerical method in conjunction with the geometry of Fig. 4 can be as follows:

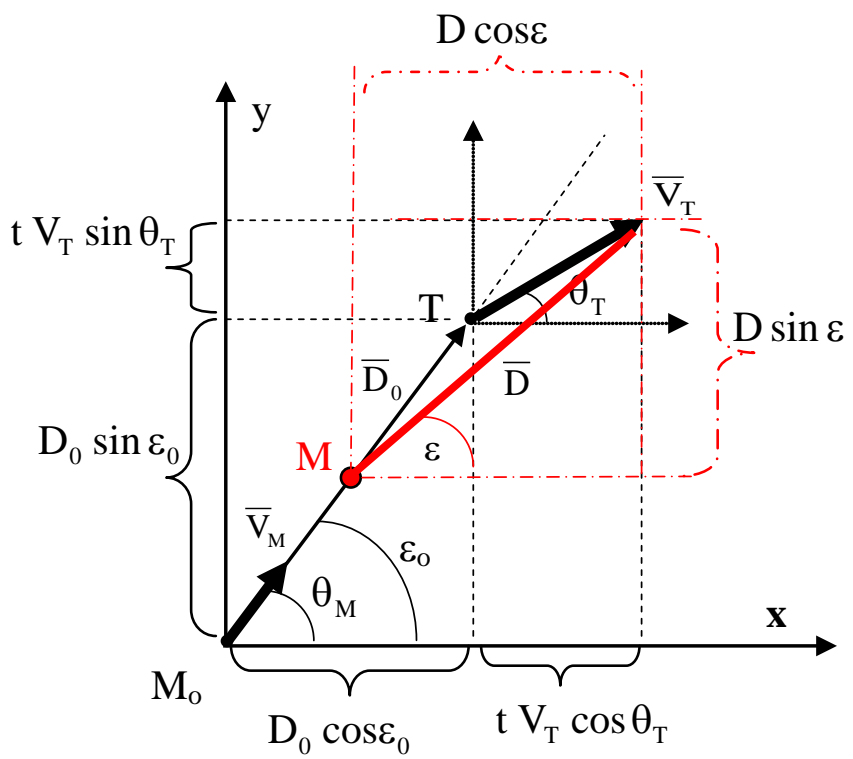

Fig. 4 Drawing Geometry

$$
\begin{aligned}
& \dot{\mathrm{D}}=\mathrm{V}_{\mathrm{T}} \cos \left(\varepsilon-\theta_{\mathrm{T}}\right)-\mathrm{V}_{\mathrm{M}} \cos \left(\varepsilon-\theta_{\mathrm{M}}\right) \\
& \dot{\varepsilon}=\left\{\mathrm{V}_{\mathrm{M}} \sin \left(\varepsilon-\theta_{\mathrm{M}}\right)-\mathrm{V}_{\mathrm{T}} \sin \left(\varepsilon-\theta_{\mathrm{T}}\right)\right\} / \mathrm{D}
\end{aligned}
$$

With one of the following equations;

$$
\begin{aligned}
& \theta_{\mathrm{M}}=\varepsilon \quad \text { (for Pure pursuit guidance method) } \\
& \theta_{\mathrm{M}}=\varepsilon-\varepsilon_{\mathrm{p}} \quad \text { (for Deviated pursuit guidance method) } \\
& \dot{\theta}_{\mathrm{M}}=\mathrm{k}_{1} \dot{\varepsilon} \quad \text { (for Proportional navigation guidance method) }
\end{aligned}
$$

Then, using the Euler's method

$$
\begin{aligned}
\mathrm{D} & =\mathrm{D}+\Delta_{\mathrm{t}} \dot{\mathrm{D}} \\
\varepsilon & =\varepsilon+\Delta_{\mathrm{t}} \dot{\varepsilon} \\
\theta_{\mathrm{M}} & =\theta_{\mathrm{M}}+\Delta_{\mathrm{t}} \dot{\theta}_{\mathrm{M}}
\end{aligned}
$$

Using the geometry shown in Fig. 6, the instantaneous position for missile and target can be obtained as follows:

$$
\begin{aligned}
& \mathrm{x}_{\mathrm{m}}=\mathrm{D}_{0} \cos \varepsilon_{0}+\mathrm{t} \mathrm{V}_{\mathrm{T}} \cos \theta_{\mathrm{T}}-\mathrm{D} \cos \varepsilon \\
& \mathrm{y}_{\mathrm{m}}=\mathrm{D}_{0} \sin \varepsilon_{0}+\mathrm{t} \mathrm{V}_{\mathrm{T}} \sin \theta_{\mathrm{T}}-\mathrm{D} \sin \varepsilon \\
& \mathrm{x}_{\mathrm{T}}=\mathrm{D}_{0} \cos \varepsilon_{0}+\mathrm{tV}_{\mathrm{T}} \cos \theta_{\mathrm{T}} \\
& \mathrm{y}_{\mathrm{T}}=\mathrm{D}_{0} \sin \varepsilon_{0}+\mathrm{t} \mathrm{V}_{\mathrm{T}} \sin \theta_{\mathrm{T}}
\end{aligned}
$$




\subsection{Analytical Solution}

\subsubsection{Constant Bearing (or Parallel Approach) Guidance Method}

\subsubsection{Straight line outgoing target trajectory}

Assuming vertical plane motion, constant velocity $\left(\mathrm{V}_{\mathrm{T}}\right.$ and $\mathrm{V}_{\mathrm{M}}$ ) for both the target and missile and constant altitude for target flight, the trajectory parameters are derived analytically using the engagement scenarios shown in Fig. 5. These assumptions simplify $\mathrm{Eq}^{\text {ns }}(7)$ into two differential equations in $\mathrm{D}$ and $\varepsilon$, the manipulation of which with calculus rules and ideal bond yield:

$$
\begin{aligned}
& \mathrm{D}=\mathrm{D}_{\mathrm{o}}+\mathrm{t}\left\{\mathrm{V}_{\mathrm{T}} \cos \eta_{\mathrm{T}}-\mathrm{V}_{\mathrm{M}} \sqrt{1-\frac{1}{\mathrm{P}^{2}} \sin ^{2} \eta_{\mathrm{T}}}\right\} \\
& \mathrm{t}_{\mathrm{f}}=\frac{\mathrm{D}_{\mathrm{o}}}{\mathrm{V}_{\mathrm{M}} \sqrt{1-\frac{1}{\mathrm{P}^{2}} \sin ^{2} \eta_{\mathrm{T}}}-\mathrm{V}_{\mathrm{T}} \cos \eta_{\mathrm{T}}}
\end{aligned}
$$

According to parallel navigation (constant bearing) rule, the line-ofsight (LOS) direction relative to the inertial coordinate system is kept constant, i.e., during guidance the LOS remains parallel to the initial LOS due to which this rule can be presented in the form, $\varepsilon=\varepsilon_{\mathrm{p}}=$ constan $\mathrm{t}$ and $\dot{\mathrm{D}}=\mathrm{V}_{\mathrm{T}} \cos \eta_{\mathrm{T}}-\mathrm{V}_{\mathrm{M}} \cos \eta_{\mathrm{M}}$. Thus, the homing condition $\dot{\mathrm{D}}<0$ is equivalent to $\mathrm{V}_{\mathrm{T}} \cos \eta_{\mathrm{T}}<\mathrm{V}_{\mathrm{M}} \cos \eta_{\mathrm{M}}$. In addition, the constant direction of the LOS necessitates the condition that

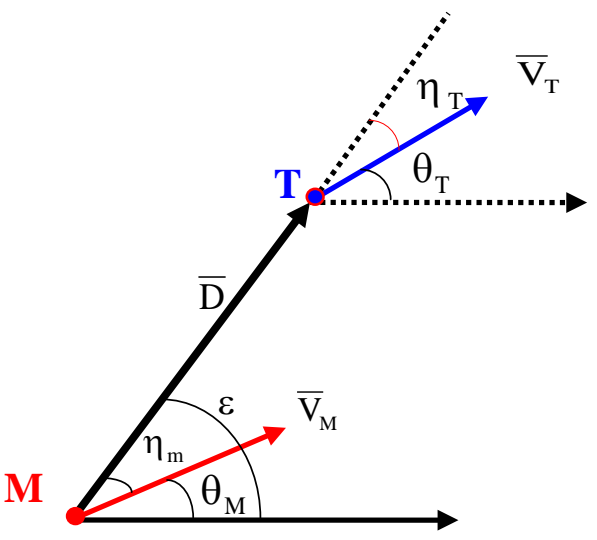

Fig. 5 Constant bearing planer geometry $\mathrm{V}_{\mathrm{T}} \sin \eta_{\mathrm{T}}=\mathrm{V}_{\mathrm{M}} \sin \eta_{\mathrm{M}}$. The engagement or collision triangle (MTI) consists of the missile target and interception positions, the vectors of their velocities, the LOS, and range vectors. The LOS angle $\varepsilon$ is measured with respect to the horizontal reference line $X$. The angle $\eta_{M}$ is called the lead angle. The angle $\left(180^{\circ}-\eta_{\mathrm{T}}\right)$ is called the aspect angle. If the above conditions are satisfied, a missile with an appropriate constant velocity can intercept the non-accelerating target. The dashed lines show the position of the missile $\mathrm{M}$ and target $\mathrm{T}$ (the position of the LOS line) according to the parallel navigation rule.

\subsubsection{Circular target trajectory}

For target moving in a circular trajectory with $\theta=-\omega \mathrm{t}, \mathrm{V}_{\mathrm{T}}$ and $\mathrm{V}_{\mathrm{M}}$ are constants in $[\mathrm{km} / \mathrm{s}]$ and $\varepsilon=90^{\circ}$; the trajectory equations can be derived as follows, Fig. 6:

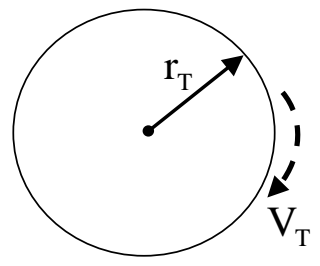

Fig. 6 Target Trajectory 


\begin{tabular}{rl|l|l|}
\hline $\mathrm{D}$ & $=\mathrm{D}_{\mathrm{o}}-\frac{2 \mathrm{~V}_{\mathrm{T}}(1-\cos \omega \mathrm{t})}{\omega \pi / 180}$ & & \\
$\theta_{\mathrm{M}}$ & $=\omega \mathrm{t}$ & (39) \\
$\mathrm{t}_{\mathrm{f}}$ & $=\frac{1}{\omega} \cos ^{-1}\left\{1-\frac{\omega \mathrm{D}_{0} \pi}{2 \mathrm{~V}_{\mathrm{T}}(180)}\right\}$ & \\
$\mathrm{r}_{\mathrm{T}}$ & $=\frac{\mathrm{V}_{\mathrm{T}}}{\omega}$ &
\end{tabular}

where $r_{T}$ is the radius of curvature of target-trajectory, the angular velocity $\omega$ is in [deg/s] and the range $\mathrm{D}$ is in $[\mathrm{km}]$.

\subsubsection{Case studies}

The derived equations $(38,39)$ are programmed within the MATLAB environments where the simulation is conducted for different engagement scenarios:

- Using target at $\mathrm{D}_{\mathrm{o}}=20[\mathrm{~km}]$, velocity $\mathrm{V}_{\mathrm{T}}=0.4[\mathrm{~km} / \mathrm{sec}]$, LOS elevation $\varepsilon_{\mathrm{o}}=30\left[^{\circ}\right]$, maneuver $\mathrm{J}_{\mathrm{N}_{\mathrm{T}}}= \pm 0.00877\left[\mathrm{~km} / \mathrm{sec}^{2}\right]$, initial flight direction $\theta_{\mathrm{T}_{\mathrm{o}}}=0\left[^{\circ}\right]$ while the missile position $\left(\mathrm{x}_{\mathrm{M}}, \mathrm{y}_{\mathrm{M}}=(0,0)[\mathrm{km}]\right)$, velocity $\mathrm{V}_{\mathrm{M}}=0.6[\mathrm{~km} / \mathrm{sec}]$, heading error $\Delta_{\varepsilon}=0\left[^{\circ}\right]$.

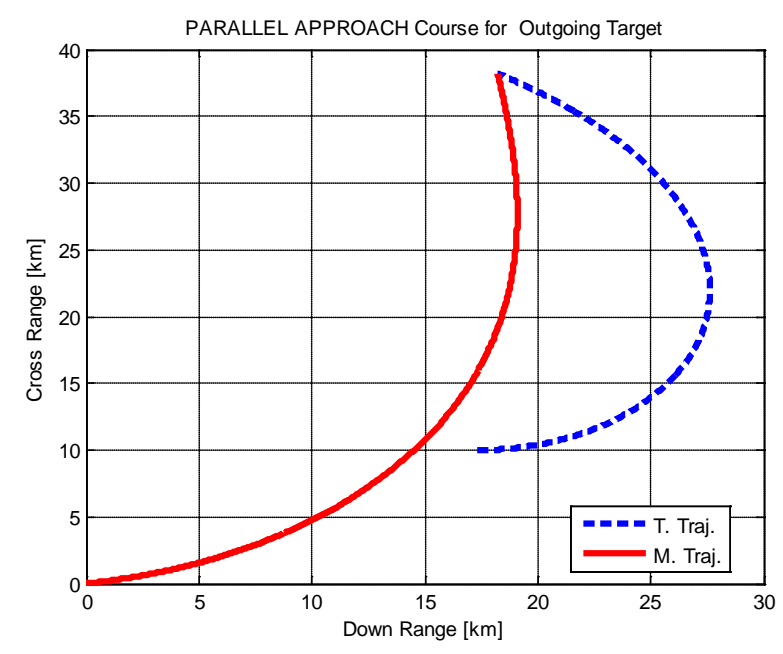

(a)

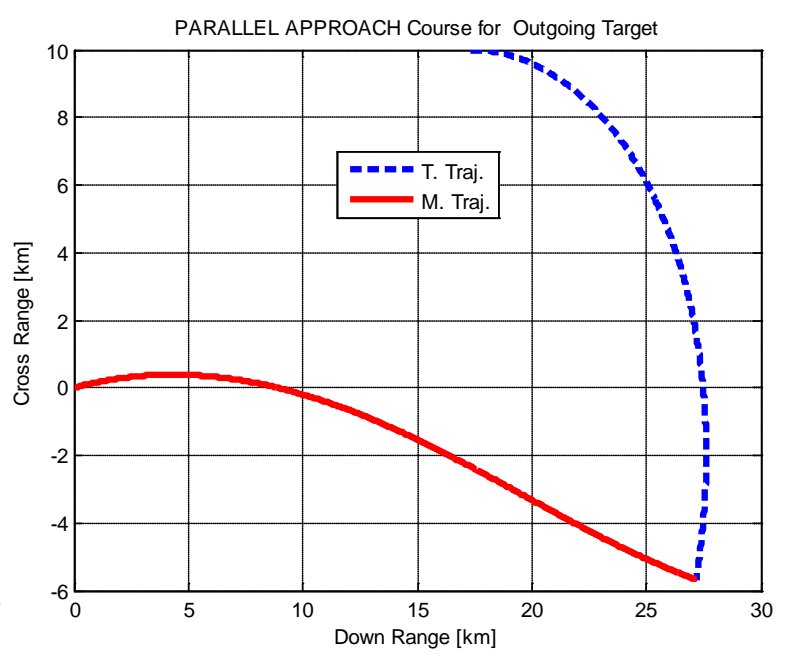

(b)

Fig. 7: CBGM with Maneuvering Target (a) $J_{N_{T}}=0.00877\left[\mathrm{~km} / \mathrm{sec}^{2}\right]$

$$
\text { and (b) } J_{N_{T}}=-0.00877\left[\mathrm{~km} / \mathrm{sec}^{2}\right]
$$

The obtained results include miss distance $D_{\text {miss }}=3.4[\mathrm{~m}]$ and time of flight $t_{f}=46.2$ [sec] with negative maneuvers while $D_{\text {miss }}=5.8[\mathrm{~m}]$ and $t_{f}=70.4[\mathrm{sec}]$ with positive maneuvers.

- Using target exercising circular maneuver at $\mathrm{D}_{\mathrm{o}}=10[\mathrm{~km}]$, and $\omega_{\mathrm{T}}=5[\% / \mathrm{sec}]$, while the missile flight position $\left(\mathrm{x}_{\mathrm{M}}, \mathrm{y}_{\mathrm{M}}=(0,0)[\mathrm{km}]\right)$, velocity $\mathrm{V}_{\mathrm{M}}=0.5[\mathrm{~km} / \mathrm{sec}]$, and heading error $\Delta_{\varepsilon}=0\left[^{\circ}\right]$. The obtained results include miss distance $D_{\text {miss }}=135[\mathrm{~m}]$ and time of flight $\mathrm{t}_{\mathrm{f}}=16.5[\mathrm{sec}]$.

\subsubsection{Pure Pursuit Guidance Method}

Assuming vertical plane motion, constant velocity for both the target and missile and constant altitude for target flight $\left(\theta_{\mathrm{T}}=0^{\circ}\right.$ or $\left.\theta_{\mathrm{T}}=180^{\circ}\right)$; the trajectory parameters are derived analytically using the engagement scenarios shown in Fig. 9. These assumptions simplify $\mathrm{Eq}^{\mathrm{ns}}(8)$ into two differential equations in $\mathrm{D}$ and $\varepsilon$, the manipulation of which with calculus rules and $\mathrm{Eq}^{\mathrm{n}}(9)$ yield the following equations: 


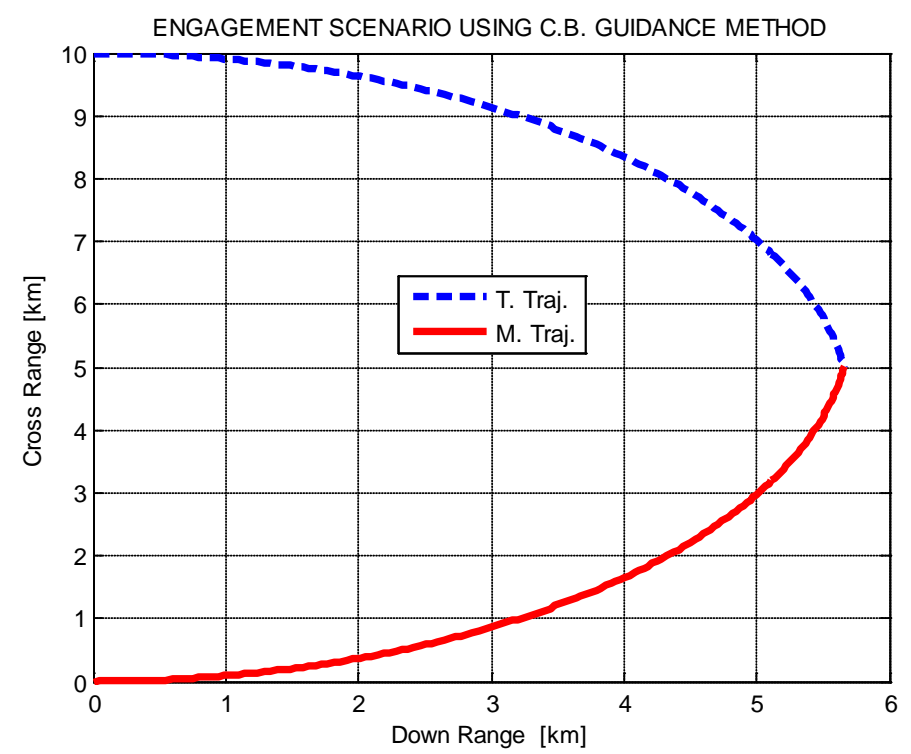

Fig. 8 CBGM with Circular Target-Trajectory
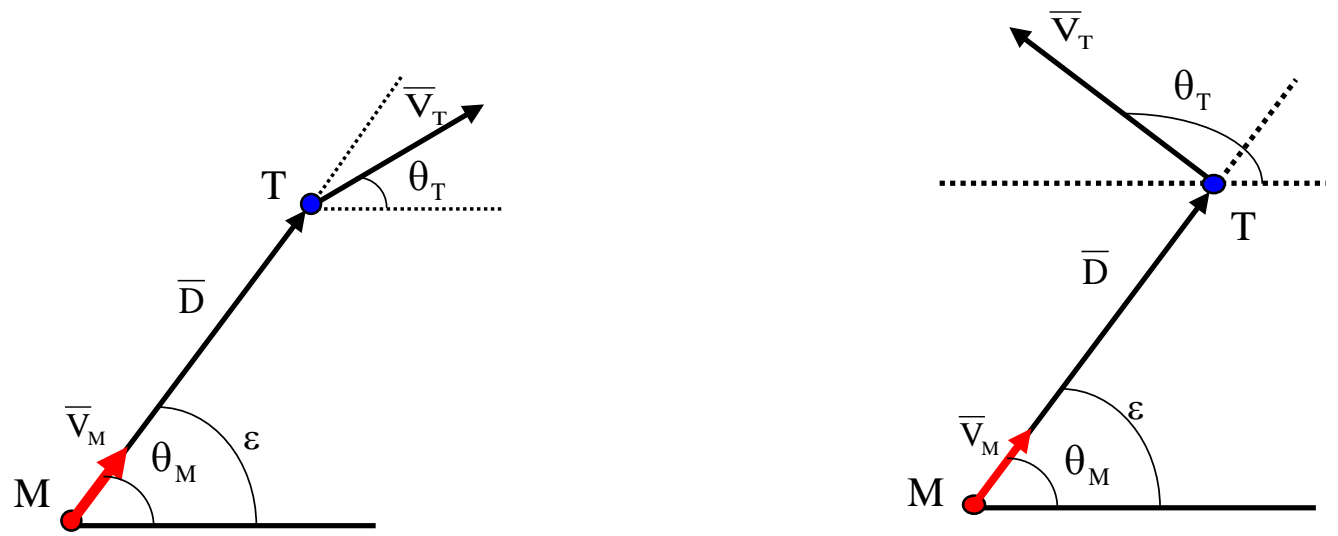

Fig. 9 Pure Pursuit Engagement

\subsubsection{Outgoing target}

$$
\begin{aligned}
& D=A \frac{(\sin \varepsilon)^{P-1}}{(1+\cos \varepsilon)^{P}} \\
& A=D_{o} \frac{\left(1+\cos \varepsilon_{o}\right)^{P}}{\left(\sin \varepsilon_{o}\right)^{P-1}} \\
& t \quad=\frac{D_{o}\left(P+\cos \varepsilon_{o}\right)-D(P+\cos \varepsilon)}{V_{T}\left(p^{2}-1\right)} \\
& \dot{\varepsilon}=\frac{-V_{T}(1+\cos \varepsilon)^{P}}{A(\sin \varepsilon)^{P-2}} \\
& J_{N}=V_{M} \dot{\varepsilon} \\
& \dot{\varepsilon}_{\max }=\dot{\varepsilon}_{\left\{\varepsilon=\cos ^{-1}\left(\frac{P}{2}\right)\right\}}=\frac{V_{T}}{A}\left\{1+\frac{P}{2}\right\}^{P}\left\{1-\left(\frac{P}{2}\right)^{2}\right\}^{1-\frac{P}{2}} \\
& P \quad=V_{M} / V_{T}
\end{aligned}
$$

The launching zone is characterized by:

$\mathrm{D}_{\mathrm{o}}=\frac{\mathrm{V}_{\mathrm{M}} \mathrm{V}_{\mathrm{T}}}{\mathrm{J}_{\mathrm{N}_{\max }}}\left\{\sin \varepsilon_{\mathrm{o}}\right\}^{\mathrm{P}-1}\left\{1+\frac{\mathrm{P}}{2}\right\}^{\mathrm{P}}\left\{1-\left(\frac{\mathrm{P}}{2}\right)^{2}\right\}^{1-\frac{\mathrm{P}}{2}}\left\{1+\cos \varepsilon_{\mathrm{o}}\right\}^{-\mathrm{P}}$ 


\subsubsection{Incoming target}

$$
\begin{aligned}
& \mathrm{D}=\mathrm{A}^{\prime} \frac{(1+\cos \varepsilon)^{\mathrm{P}}}{(\sin \varepsilon)^{\mathrm{P}+1}} \\
& \mathrm{~A}^{\prime}=\mathrm{D}_{\mathrm{o}} \frac{\left(\sin \varepsilon_{\mathrm{o}}\right)^{\mathrm{P}+1}}{\left(1+\cos \varepsilon_{\mathrm{o}}\right)^{\mathrm{P}}} \\
& \mathrm{t}=\frac{\mathrm{D}_{\mathrm{o}}\left(\cos \varepsilon_{\mathrm{o}}-\mathrm{P}\right)-\mathrm{D}(\cos \varepsilon-\mathrm{P})}{\mathrm{V}_{\mathrm{T}}\left(1-\mathrm{p}^{2}\right)} \\
& \dot{\varepsilon}=\frac{\mathrm{V}_{\mathrm{T}}(\sin \varepsilon)^{\mathrm{P}+2}}{\mathrm{~A}^{\prime}(1+\cos \varepsilon)^{\mathrm{P}}} \\
& \mathrm{J}_{\mathrm{N}}=\mathrm{V}_{\mathrm{M}} \dot{\varepsilon} \\
& \dot{\varepsilon}_{\max }=\dot{\varepsilon}_{\left\{\varepsilon=\cos ^{-1}\left(-\frac{\mathrm{P}}{2}\right)\right\}}=\frac{\mathrm{V}_{\mathrm{T}}}{\mathrm{A}^{\prime}}\left\{1-\left(\frac{\mathrm{P}}{2}\right)^{2}\right\}^{\frac{\mathrm{P}}{2}+1}\left\{1-\frac{\mathrm{P}}{2}\right\}^{-\mathrm{P}}
\end{aligned}
$$

The launching zone is characterized by: $\left[\mathrm{J}_{\mathrm{N}_{\max }}=\mathrm{V}_{\mathrm{M}} \dot{\varepsilon}_{\max }\right]$

$$
\mathrm{D}_{\mathrm{o}}=\frac{\mathrm{V}_{\mathrm{M}} \mathrm{V}_{\mathrm{T}}}{\mathrm{J}_{\mathrm{N}_{\max }}} \frac{\left(1+\cos \varepsilon_{\mathrm{o}}\right)^{\mathrm{P}}}{\left(\sin \varepsilon_{\mathrm{o}}\right)^{\mathrm{P}+1}}\left\{1-\left(\frac{\mathrm{P}}{2}\right)^{2}\right\}^{\frac{\mathrm{P}}{2}+1}\left\{1-\frac{\mathrm{P}}{2}\right\}^{-\mathrm{P}}
$$

The above equations are programmed as functions within the MATLAB environment (or any high level language) and the simulation is conducted using different engagements' scenarios as described in the following sub-sections.

\subsubsection{Case studies}

Many engagement scenarios are used, among them are the following:

- Using a target maneuvering at $\left(\mathrm{x}_{\mathrm{t}}, \mathrm{y}_{\mathrm{t}}\right)=(36,10)[\mathrm{km}]$, velocity $\mathrm{V}_{\mathrm{T}}=0.2[\mathrm{~km} / \mathrm{sec}]$, maneuver $\mathrm{J}_{\mathrm{N}_{\mathrm{T}}}= \pm 0.005\left[\mathrm{~km} / \mathrm{sec}^{2}\right]$, either approaching or outgoing, while the missile position $\left(\mathrm{x}_{\mathrm{M}}, \mathrm{y}_{\mathrm{M}}=(0,0)[\mathrm{km}]\right)$, velocity $\mathrm{V}_{\mathrm{M}}=0.8[\mathrm{~km} / \mathrm{sec}]$, heading error $\Delta_{\varepsilon}=0\left[{ }^{\circ}\right]$.

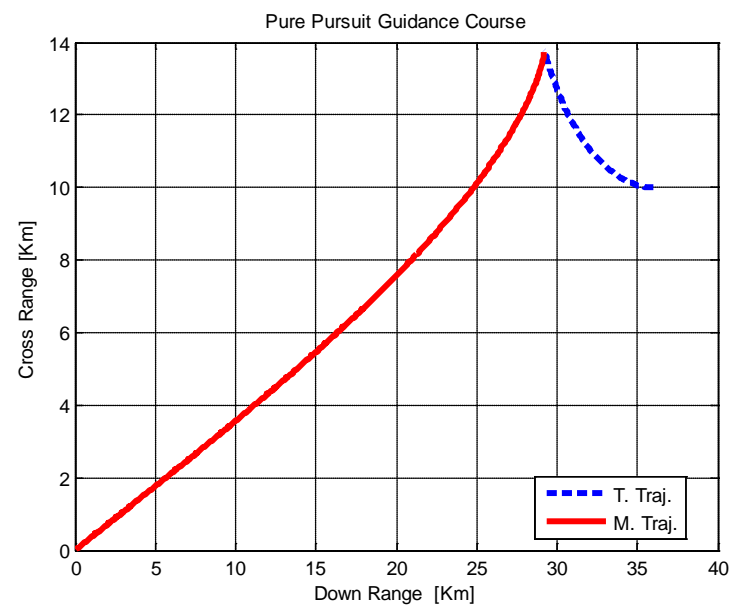

(a)

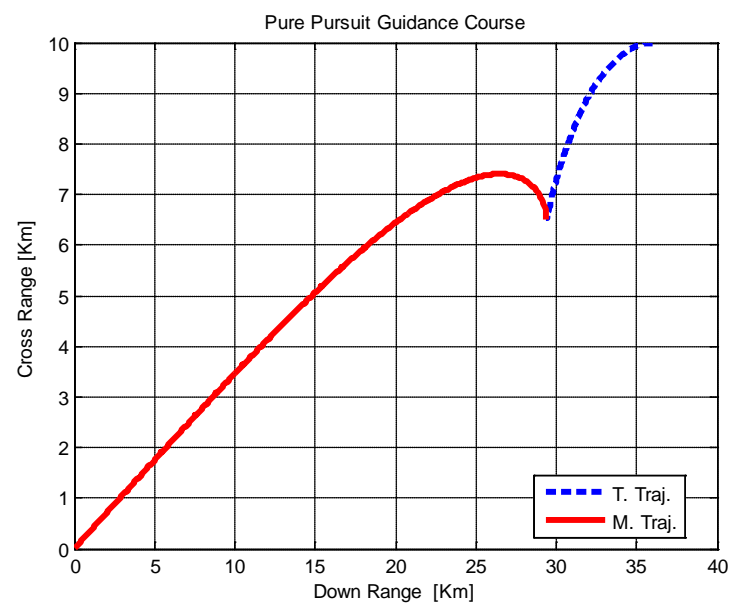

(b)

Fig. 10: PPGM with maneuvering target (a) $\mathrm{J}_{\mathrm{N}_{\mathrm{T}}}=0.005\left[\mathrm{~km} / \mathrm{sec}^{2}\right]$ and

(b) $\mathrm{J}_{\mathrm{N}_{\mathrm{T}}}=-0.005\left[\mathrm{~km} / \mathrm{sec}^{2}\right]$ 
The obtained results include miss distance $D_{\text {miss }}=47.3[\mathrm{~m}]$ and time of flight $t_{f}=40.5$ [sec] with positive maneuvers while $\mathrm{D}_{\text {miss }}=25.5[\mathrm{~m}]$ and $t_{\mathrm{f}}=38.8$ [sec] with negative maneuvers. The results clarify the weakness of this guidance method due to the severe demanded normal acceleration near the impact point especially with approaching targets.

- For the simulation analysis to be nearer to the reality, the missile velocity can be described in time-varying form as

$$
\mathrm{V}_{\mathrm{m}}= \begin{cases}0.4+0.35 \mathrm{t}[\mathrm{km} / \mathrm{sec}] & \mathrm{t}<2[\mathrm{sec}] \\ 1.3 \mathrm{e}^{0.0995 \mathrm{t}} \quad[\mathrm{km} / \mathrm{sec}] & \mathrm{t} \geq 2[\mathrm{sec}]\end{cases}
$$

Using this velocity and different flight parameters yield the trajectories shown in Fig. 11.
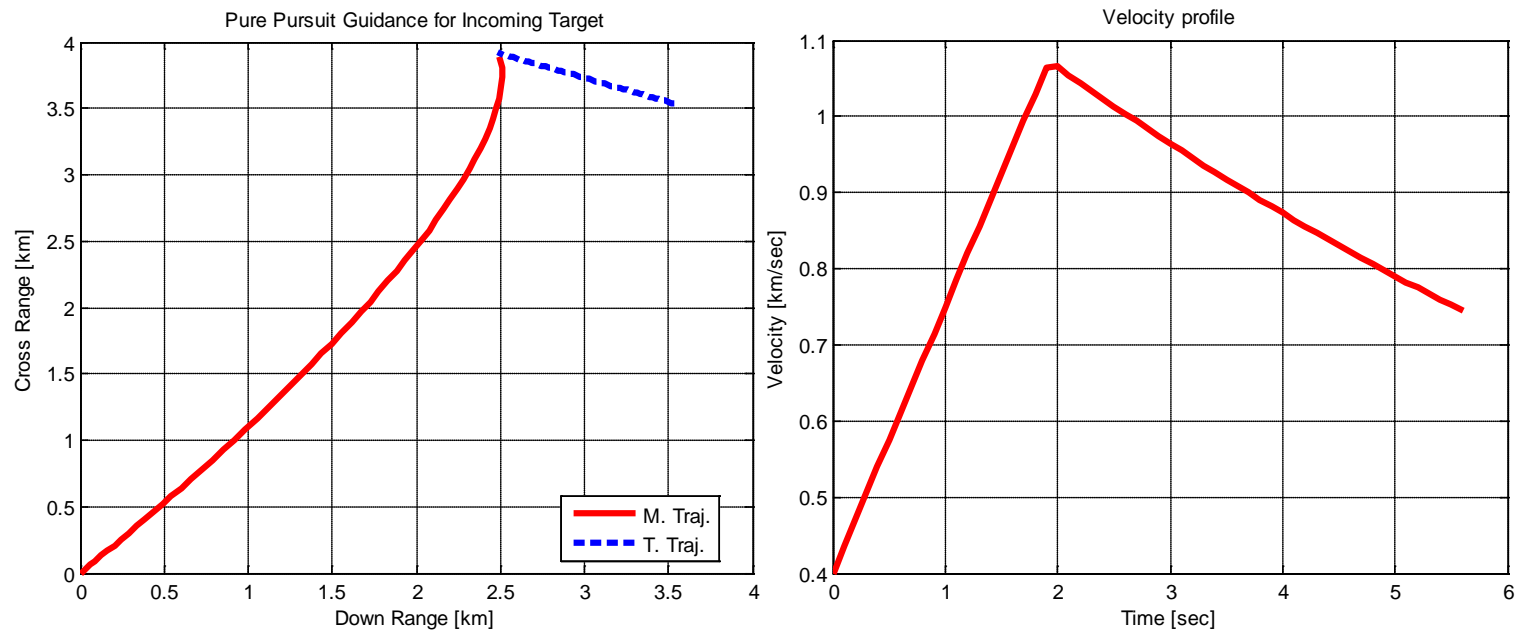

Fig. 11: PPGM using $\mathbf{D}_{0}=5[\mathrm{~km}], \varepsilon_{0}=45^{\circ}, \theta_{\mathrm{T}}=160^{\circ}, \mathbf{V}_{\mathrm{T}}=\mathbf{0 . 2}[\mathbf{k m} / \mathbf{s e c}]$

\subsubsection{Deviated Pursuit Guidance Method}

Assuming vertical plane motion, constant velocity for both the target and missile and constant altitude for target flight, the trajectory parameters are derived analytically using the engagement scenarios shown in Fig. 12. These assumptions simplify $\mathrm{Eq}^{\text {ns }}(7)$ into two differential equations in $\mathrm{D}$ and $\varepsilon$ the manipulation of which with calculus rules and $\mathrm{Eq}^{\mathrm{n}}(11)$ yield the following equations:

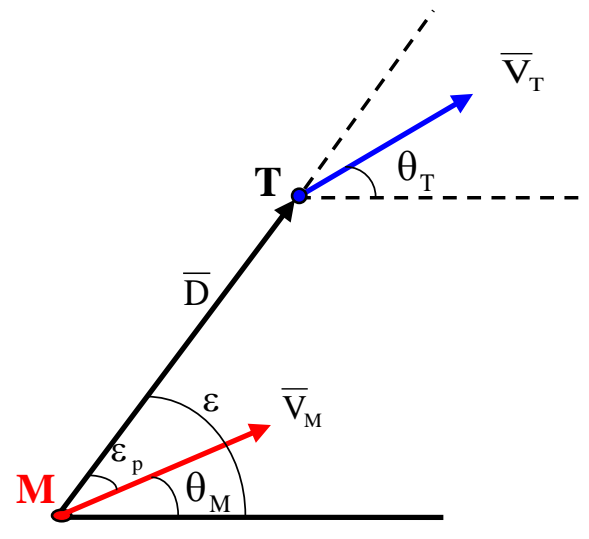

Fig. 12 Deviated Pursuit Geometry 


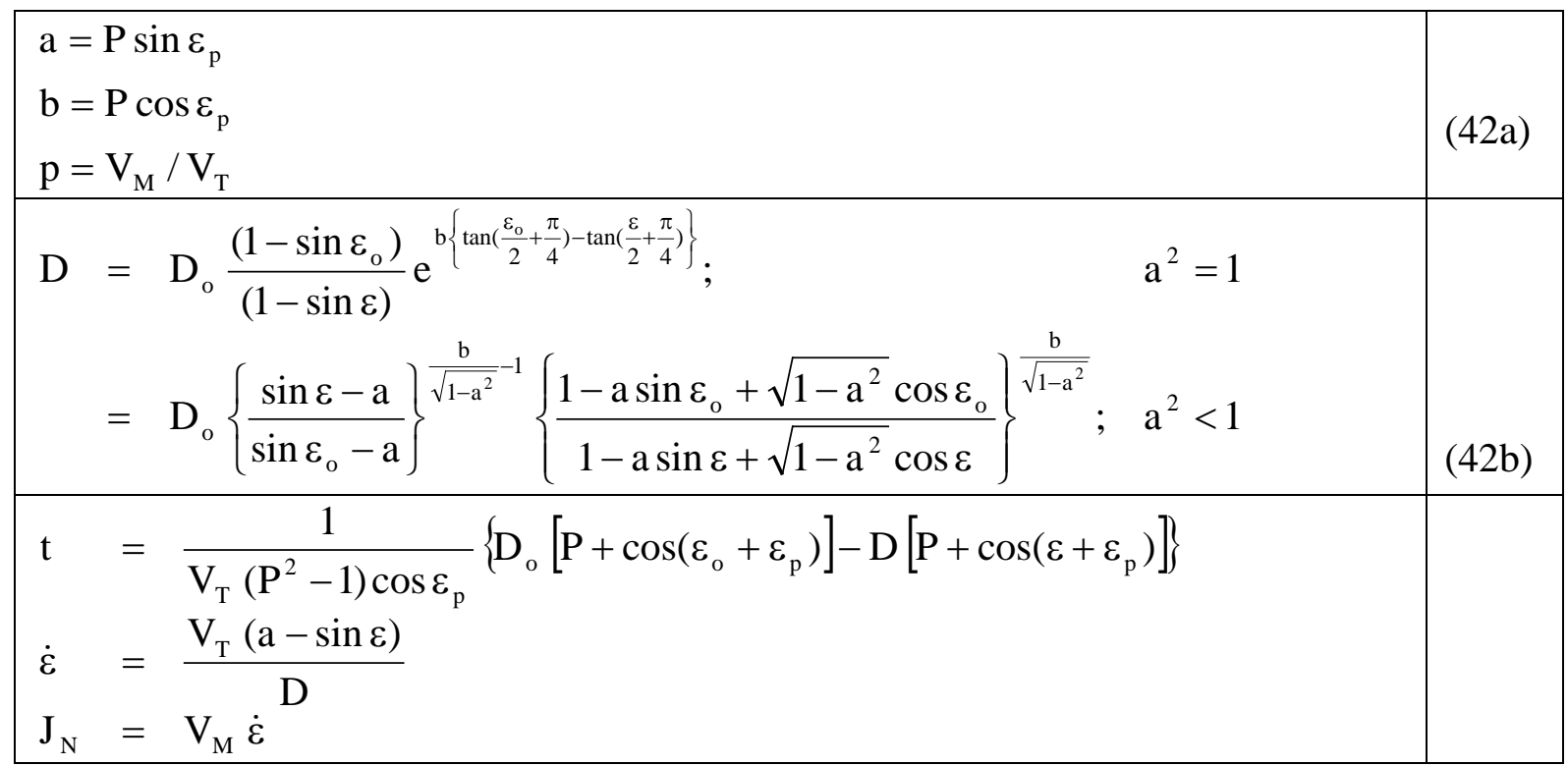

Considering a target at $\mathrm{D}_{\mathrm{o}}=37[\mathrm{~km}]$, LOS elevation $\varepsilon_{\mathrm{o}}=35^{\circ}$, velocity $\mathrm{V}_{\mathrm{T}}=0.2[\mathrm{~km} / \mathrm{sec}]$, maneuver $\mathrm{J}_{\mathrm{N}_{\mathrm{T}}}=0.0\left[\mathrm{~km} / \mathrm{sec}^{2}\right]$, initial flight direction $\theta_{\mathrm{T}_{\mathrm{o}}}=0\left[^{\circ}\right]$ while the missile position $\left(\mathrm{x}_{\mathrm{M}}, \mathrm{y}_{\mathrm{M}}=(0,0)[\mathrm{km}]\right)$, velocity $\mathrm{V}_{\mathrm{M}}=0.8[\mathrm{~km} / \mathrm{sec}]$, heading error $\Delta_{\varepsilon}=0\left[^{\circ}\right]$.
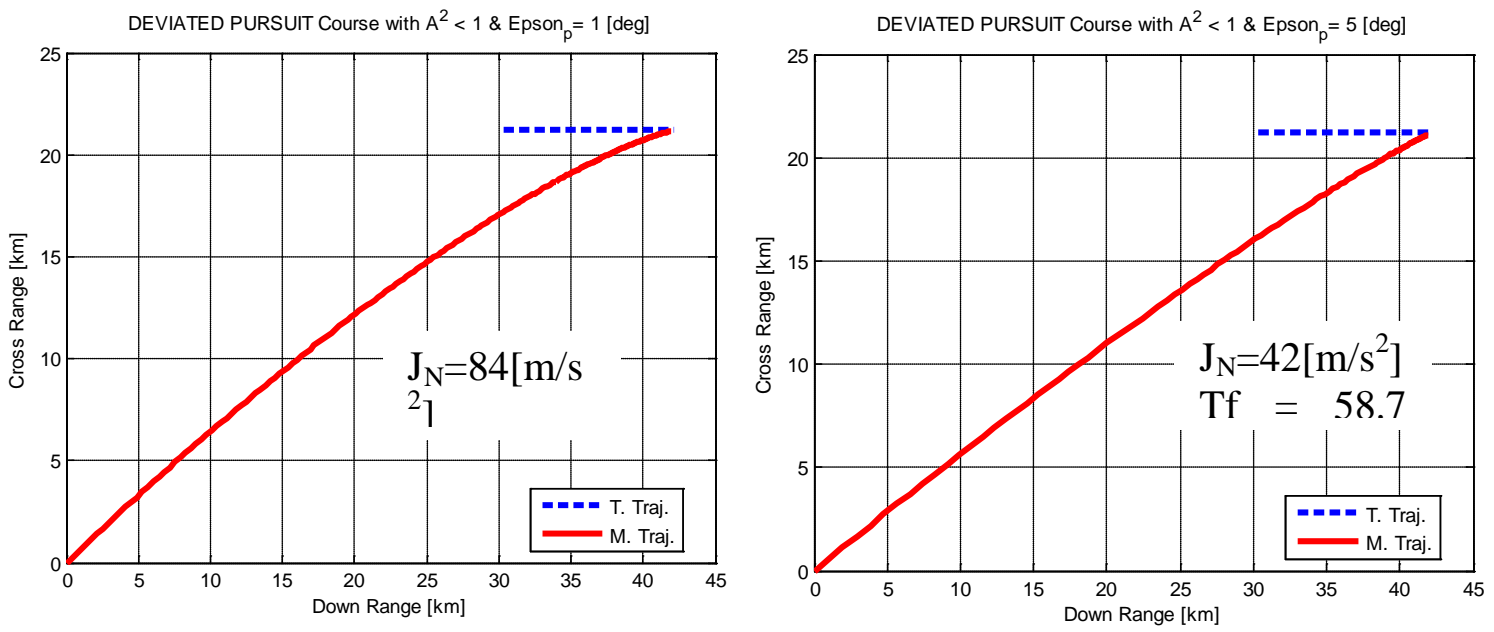

Fig. 13: Flight path using deviated pursuit guidance

The obtained results include miss distance $D_{\text {miss }}=200[\mathrm{~m}]$ and time of flight $t_{f}=59$ [sec] with positive lead angle $\varepsilon_{\mathrm{p}}=1^{\circ}$ while $\mathrm{D}_{\text {miss }}=210[\mathrm{~m}]$ and $\mathrm{t}_{\mathrm{f}}=58.7[\mathrm{sec}$ ] with the lead angle $\varepsilon_{\mathrm{p}}=5^{\circ}$. The results clarify that using greater heading angle gives less demanded normal acceleration and nearly straight line trajectory.

Using target at $\mathrm{D}_{\mathrm{o}}=45[\mathrm{~km}]$, LOS elevation $\varepsilon_{\mathrm{o}}=120^{\circ}$, velocity $\mathrm{V}_{\mathrm{T}}=0.4[\mathrm{~km} / \mathrm{sec}]$, maneuver $\mathrm{J}_{\mathrm{N}_{\mathrm{T}}}=0.0\left[\mathrm{~km} / \mathrm{sec}^{2}\right]$, while the missile position $\left(\mathrm{x}_{\mathrm{M}}, \mathrm{y}_{\mathrm{M}}=(0,0)[\mathrm{km}]\right)$, velocity $\mathrm{V}_{\mathrm{M}}=0.9[\mathrm{~km} / \mathrm{sec}]$, and different heading error $\varepsilon_{\mathrm{p}}=0^{\circ}, 5^{\circ}$, Fig. 14, 15.

The results using the DPGM for different heading angle $\varepsilon_{\mathrm{p}}$ are summarized in the following table; 


\begin{tabular}{|l|l|l|l|l|l|l|l|}
\hline Target & No & Fig. & $\varepsilon_{\mathrm{p}}\left[{ }^{\circ}\right]$ & $\mathrm{t}_{\mathrm{f}}[\mathrm{sec}]$ & $\mathrm{J}_{\mathrm{N}}[\mathrm{g}]$ & $\mathrm{J}_{\mathrm{N}}$ & $\mathrm{D}_{\text {miss }}[\mathrm{m}]$ \\
\hline Incoming & 1 & $14 \mathrm{a}$ & 0 & 48.066 & 25 & $\mathrm{~J}_{\mathrm{N}_{1}}$ & 201.4 \\
\cline { 2 - 8 } & 2 & $14 \mathrm{~b}$ & 5 & 46.216 & 36 & $1.44 \mathrm{~J}_{\mathrm{N}_{1}}$ & 201.4 \\
\cline { 2 - 8 } & 3 & $15 \mathrm{a}$ & 10 & 44.839 & 52 & $2.08 \mathrm{~J}_{\mathrm{N}_{1}}$ & 200.6 \\
\cline { 2 - 8 } & 4 & Not shown & -5 & 50.404 & 19 & $0.76 \mathrm{~J}_{\mathrm{N}_{1}}$ & 201.1 \\
\cline { 2 - 8 } & 5 & $15 \mathrm{~b}$ & -10 & 53.267 & 16 & $0.64 \mathrm{~J}_{\mathrm{N}_{1}}$ & 201.5 \\
\hline
\end{tabular}

The results show that guiding the missile using this method with the velocity heading the LOS leads to greater demanded normal acceleration that increases with the heading angle $\varepsilon_{\mathrm{p}}$. While guiding the missile using this method with the velocity lagging the LOS leads to less demanded normal acceleration that decreases with the negativeness of the heading angle $\varepsilon_{\mathrm{p}}$. Therefore, for attacking outgoing (incoming) targets using deviated pure-pursuit method it is necessary to guide the missile such that the velocity is heading (lagging) the LOS with greater angles as possible $\varepsilon_{\mathrm{p}}\left(-\varepsilon_{\mathrm{p}}\right)$.
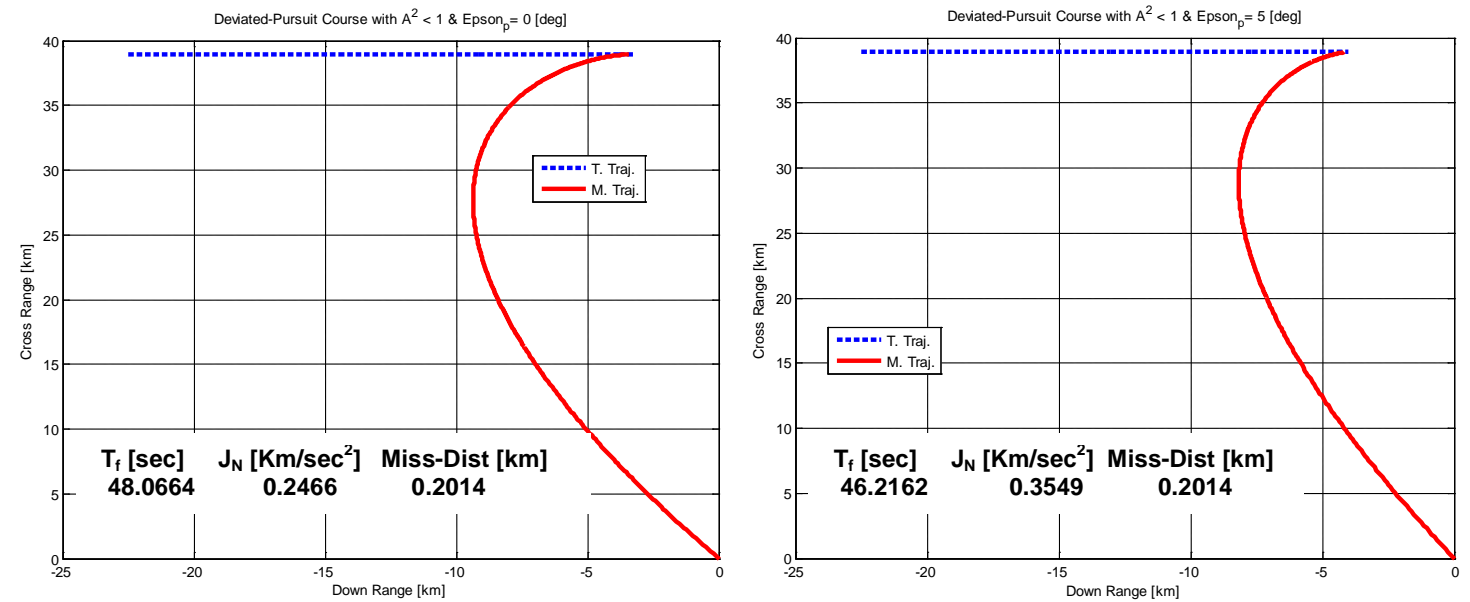

Fig. 14: DPGM using (a) $\varepsilon_{p}=0^{\circ}$ and (b) $\varepsilon_{p}=5^{\circ}$
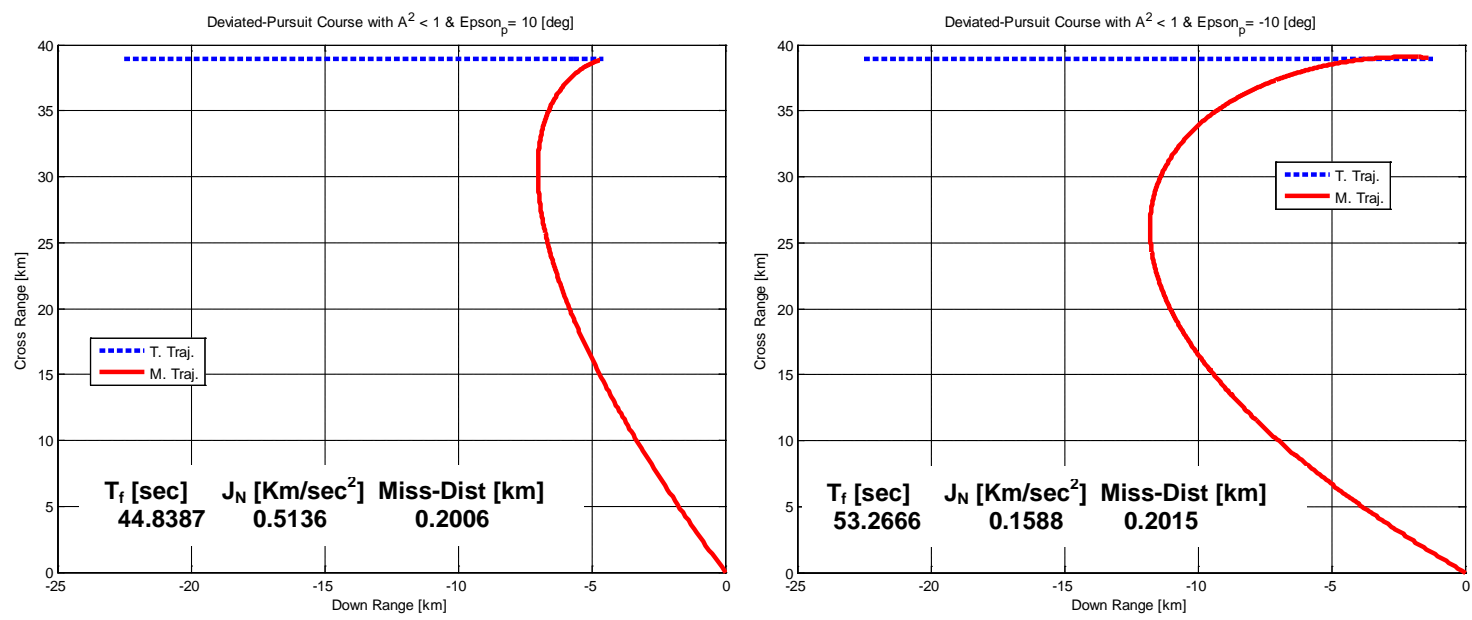

Fig. 15: DPGM using (a) $\varepsilon_{p}=10^{\circ}$ and (b) $\varepsilon_{p}=-10^{\circ}$ 


\subsubsection{Proportional Navigation Guidance Method}

The proportional navigation guidance method is considered a general homing guidance method and consequently this section is devoted to analyze it more via analytic derivation and numerical solution.

\subsubsection{Analytic approach for the trajectory derivation of PNGM}

Assuming vertical plane motion, constant velocity $\left(\mathrm{V}_{\mathrm{T}}\right.$ and $\mathrm{V}_{\mathrm{M}}$ ) for both the target and missile and constant altitude for target flight; the trajectory parameters are derived analytically using the engagement scenarios shown in Fig. 16. These assumptions simplify $\mathrm{Eq}^{\mathrm{ns}}(7)$ into two differential equations in $\mathrm{D}$ and $\varepsilon$, the manipulation of which with calculus rules and $\mathrm{Eq}^{\mathrm{n}}(12)$ yield the following equations:

Let us consider the following definitions:

$$
\begin{aligned}
\alpha_{0} & =\varepsilon_{0}+\eta_{o} \\
\mathrm{a} & =\mathrm{P}-\cos \alpha_{\mathrm{o}} \\
\mathrm{b} & =\sin \alpha_{\mathrm{o}} \\
\mathrm{c} & =\mathrm{P}+\cos \alpha_{\mathrm{o}}
\end{aligned}
$$

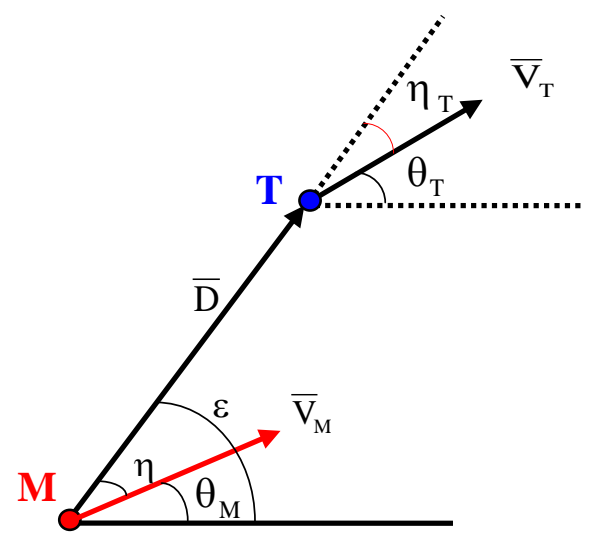

Fig. 16 P.N. Geometry

Then, the trajectory equations are derived using the tables of integrals as follow:

$$
\begin{aligned}
\mathrm{D} & =\mathrm{D}_{\mathrm{o}}\left\{\frac{\mathrm{P} \sin \eta+\sin \left(\eta-\alpha_{0}\right)}{\mathrm{P} \sin \eta_{\mathrm{o}}+\sin \left(\eta_{\mathrm{o}}-\alpha_{\mathrm{o}}\right)}\right\}^{\frac{\mathrm{P}^{2}-1}{\mathrm{P}^{2}+2 \mathrm{P} \cos \alpha_{0}+1}} \mathrm{e}^{\frac{2 \mathrm{P}\left(\eta_{0}-\eta\right) \sin \alpha_{0}}{\mathrm{P}^{2}+2 \mathrm{P} \cos \alpha_{0}+1}} \\
\dot{\varepsilon} & =\frac{\mathrm{V}_{\mathrm{T}}}{\mathrm{D}_{\mathrm{o}}}\left\{\mathrm{P} \sin \eta_{\mathrm{o}}-\sin \varepsilon_{\mathrm{o}}\right\}\left\{\frac{\mathrm{D}}{\mathrm{D}_{\mathrm{o}}}\right\}^{\frac{2\left(1+\mathrm{P} \cos \alpha_{0}\right)}{\mathrm{P}^{2}-1}} \mathrm{e}^{\frac{2 \mathrm{P}\left(\eta-\eta_{0}\right) \sin \alpha_{0}}{\mathrm{P}^{2}-1}} \\
\dot{\theta}_{\mathrm{M}} & =\mathrm{K} \dot{\varepsilon} \\
\mathrm{J}_{\mathrm{N}} & =\mathrm{V}_{\mathrm{M}} \dot{\theta}_{\mathrm{M}}
\end{aligned}
$$

\subsubsection{Incremental approach for the trajectory derivation of PNGM}

The first missile used the proportional navigation guidance (PNG) method is the German's LARK missile in the late fifties. Since that time the PNG has been used in virtually all of the world's tactical radio, infrared (IR) and television (TV) guided missiles. The popularity of this interceptor guidance law is based upon its simplicity, effectiveness and ease of implementation. Nowadays, the PN trajectory is adopted by nearly all homing guided missiles. The missile tracks the target continuously as it approaches the expected impact point, where the collision is guaranteed if the instantaneous LOS is parallel to the initial LOS. The missile homing head establishes this LOS and measures its rate of swinging in space using rate gyros. This rate is utilized to change the missile flight path accordingly and continuously until interception with the target. The PNG law issues acceleration commands, perpendicular to the instantaneous missile-target line-of-sight (LOS), which is proportional to the LOS rate and closing velocity according to the following relationship:

$\mathrm{J}_{\mathrm{N}}=\mathrm{NV}_{\mathrm{c}} \dot{\varepsilon}$

where; $\mathrm{J}_{\mathrm{N}}$ the acceleration command in $\left[\mathrm{ft} / \mathrm{sec}^{2}\right]$ or $\left[\mathrm{m} / \mathrm{sec}^{2}\right]$ or $\mathrm{g}^{\mathrm{s}}, \mathrm{N}$ is a unit-less effective navigation ratio/constant/gain chosen by the designer (may be 3-5), $\mathrm{V}_{\mathrm{c}}$ the missile-target closing velocity in $[\mathrm{ft} / \mathrm{sec}]$ or $[\mathrm{m} / \mathrm{sec}], \varepsilon$ the LOS angle in [rad] and $\dot{\varepsilon}$ the LOS rate in [rad/sec]. In tactical radar homing missile using PNG, the seeker provides an effective measurement of the LOS rate and the Doppler radar provides closing velocity information. 
While, in IR missile using PNG, the LOS rate is measured whereas the closing velocity is estimated/ guesstimated. In tactical endo-atmospheric missiles, PNG commands are usually implemented by moving fins or other control surfaces to obtain the required lift. While, exoatmospheric strategic interceptors use thrust vector control, lateral divert engines or squibs to achieve the desired acceleration levels.

Consider the two-dimensional point mass missile-target engagement geometry shown in Fig. 17, where $\mathrm{M}$ is the missile, $\mathrm{T}$ is the target and $\mathrm{I}$ is the interception point forming the collision triangle MTI. For driving the equations of missile motion, consider the following assumptions: $\mathrm{X}$ and $\mathrm{Y}$-axes are the reference axes, both the missile and target travel at constant velocity, and the missile velocity vector $\bar{V}_{M}$ is heading at angle $\left(\varepsilon_{\mathrm{P}}+\Delta_{\varepsilon}\right)$ w.r.t. the LOS. Where $\varepsilon_{\mathrm{p}}$ is the missile lead angle, $\Delta_{\varepsilon}$ is the missile heading error, $\boldsymbol{\varepsilon}$ the LOS heading angle, and D the missile-target separation.

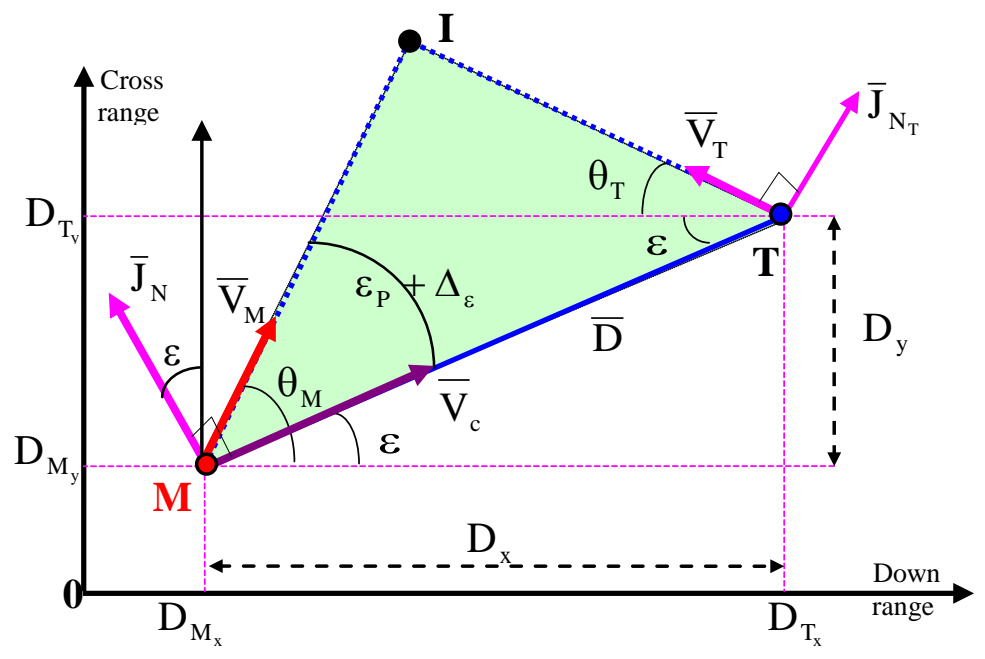

Fig. 17: 2D Missile-Target engagement geometry

The closing velocity $\left(\mathrm{V}_{\mathrm{c}}\right)$ is defined to be the negative rate of change of the distance from missile to target i.e.

$$
\mathrm{V}_{\mathrm{c}}=-\dot{\mathrm{D}}
$$

Therefore, at the end of engagement when the missile and target are in closest proximity the sign of $\mathrm{V}_{\mathrm{c}}$ will change. The desired acceleration command $\mathrm{J}_{\mathrm{N}}$ is perpendicular to the instantaneous LOS. The target can maneuver evasively with acceleration magnitude $\mathrm{J}_{\mathrm{N}_{\mathrm{T}}}$, which is perpendicular to the target velocity vector. That is, the target maneuver is given by

$$
\mathrm{J}_{\mathrm{N}_{\mathrm{T}}}=\mathrm{V}_{\mathrm{T}} \dot{\theta}_{\mathrm{T}} \quad \text { or } \quad \dot{\theta}_{\mathrm{T}}=\frac{\mathrm{J}_{\mathrm{N}_{\mathrm{T}}}}{\mathrm{V}_{\mathrm{T}}}
$$

where $\dot{\theta}_{\mathrm{T}}$ is the angular velocity of the target and $\mathrm{V}_{\mathrm{T}}$ is the magnitude of target velocity. Integrating $\mathrm{Eq}^{\mathrm{n}}$ (46), the components of target velocity along the inertial reference axes can be obtained as follows:

$$
\mathrm{V}_{\mathrm{T}_{\mathrm{x}}}=-\mathrm{V}_{\mathrm{T}} \cos \theta_{\mathrm{T}} \quad \& \quad \mathrm{~V}_{\mathrm{T}_{\mathrm{y}}}=\mathrm{V}_{\mathrm{T}} \sin \theta_{\mathrm{T}}
$$

The direct integration of $\mathrm{Eq}^{\mathrm{n}}$ (47) leads to the instantaneous target position in the reference frame $\langle$ oxy $\rangle$ as follows:

$$
\begin{aligned}
& \dot{\mathrm{D}}_{\mathrm{T}_{\mathrm{x}}}=\mathrm{V}_{\mathrm{T}_{\mathrm{x}}} \\
& \dot{\mathrm{D}}_{\mathrm{T}_{\mathrm{y}}}=\mathrm{V}_{\mathrm{T}_{\mathrm{y}}}
\end{aligned}
$$

Similarly, the missile velocity and position components are given by the following differential equations:

$$
\begin{aligned}
& \dot{\mathrm{V}}_{\mathrm{M}_{\mathrm{x}}}=\mathrm{J}_{\mathrm{N}_{\mathrm{x}}} \text { and } \begin{array}{l}
\dot{\mathrm{D}}_{\mathrm{M}_{\mathrm{x}}}=\mathrm{V}_{\mathrm{M}_{\mathrm{x}}} \\
\dot{\mathrm{V}}_{\mathrm{M}_{\mathrm{y}}}=\mathrm{J}_{\mathrm{N}_{\mathrm{y}}}
\end{array} \text { 的 }
\end{aligned}
$$


where; $\mathrm{J}_{\mathrm{N}_{\mathrm{x}}}$ and $\mathrm{J}_{\mathrm{N}_{\mathrm{y}}}$ are the missile acceleration components along the reference axes. To calculate these components, the components of the relative missile-target separation have to be found first as follows:

$$
\begin{aligned}
& \mathrm{D}_{\mathrm{x}}=\mathrm{D}_{\mathrm{T}_{\mathrm{x}}}-\mathrm{D}_{\mathrm{M}_{\mathrm{x}}} \\
& \mathrm{D}_{\mathrm{y}}=\mathrm{D}_{\mathrm{T}_{\mathrm{y}}}-\mathrm{D}_{\mathrm{M}_{\mathrm{y}}}
\end{aligned}
$$

The LOS angle can be obtained according to Fig. 18 as follows:

$$
\varepsilon=\tan ^{-1}\left(D_{\mathrm{y}} / \mathrm{D}_{\mathrm{x}}\right)
$$

Let us define the relative velocity components in the inertial reference coordinates as follows:

$$
\begin{aligned}
& \dot{\mathrm{D}}_{\mathrm{x}} \equiv \mathrm{V}_{\mathrm{TM}_{\mathrm{x}}}=\mathrm{V}_{\mathrm{T}_{\mathrm{x}}}-\mathrm{V}_{\mathrm{M}_{\mathrm{x}}} \\
& \dot{\mathrm{D}}_{\mathrm{y}} \equiv \mathrm{V}_{\mathrm{TM}_{\mathrm{y}}}=\mathrm{V}_{\mathrm{T}_{\mathrm{y}}}-\mathrm{V}_{\mathrm{M}_{\mathrm{y}}}
\end{aligned}
$$

The direct differentiation of $\mathrm{Eq}^{\mathrm{n}}$ (51) gives the LOS rate as follows:

$$
\dot{\varepsilon}=\frac{1}{1+\left(\frac{D_{y}}{D_{x}}\right)^{2}} \cdot \frac{d}{d t}\left[\frac{D_{y}}{D_{x}}\right]=\frac{D_{x}^{2}}{D_{x}^{2}+D_{y}^{2}} \cdot \frac{D_{x} \dot{D}_{y}-D_{y} \dot{D}_{x}}{D_{x}^{2}}=\frac{D_{x} \dot{D}_{y}-D_{y} \dot{D}_{x}}{D_{x}^{2}+D_{y}^{2}}=\frac{D_{x} V_{T_{y}}-D_{y} V_{T_{x}}}{D^{2}}
$$

where; $\mathrm{D}=\sqrt{\mathrm{D}_{\mathrm{x}}^{2}+\mathrm{D}_{\mathrm{y}}^{2}}$ is the relative separation between missile and target. Then, the closing velocity is obtained according to $\mathrm{Eq}^{\mathrm{n}}(45)$ as follows:

$$
\mathrm{V}_{\mathrm{c}} \equiv-\dot{\mathrm{D}}=-\frac{1}{2}\left(\mathrm{D}_{\mathrm{x}}^{2}+\mathrm{D}_{\mathrm{y}}^{2}\right)^{-\frac{1}{2}}\left(2 \mathrm{D}_{\mathrm{x}} \dot{\mathrm{D}}_{\mathrm{x}}+2 \mathrm{D}_{\mathrm{y}} \dot{\mathrm{D}}_{\mathrm{y}}\right)=-\frac{\mathrm{D}_{\mathrm{x}} \mathrm{V}_{\mathrm{TM}_{\mathrm{x}}}+\mathrm{D}_{\mathrm{y}} \mathrm{V}_{\mathrm{TM}_{\mathrm{y}}}}{\mathrm{D}}
$$

Now, the magnitude of missile guidance command $\mathrm{J}_{\mathrm{N}}$ can be given according to the PNG law as given in $\mathrm{Eq}^{\mathrm{n}}$ (45). This acceleration command is perpendicular to the instantaneous LOS and therefore its components in the inertial reference coordinates are given by the following relationships:

$$
\begin{aligned}
& \mathrm{J}_{\mathrm{N}_{\mathrm{x}}}=-\mathrm{J}_{\mathrm{N}} \sin \varepsilon \\
& \mathrm{J}_{\mathrm{N}_{\mathrm{y}}}=\mathrm{J}_{\mathrm{N}} \cos \varepsilon
\end{aligned}
$$

The complete set of differential equations required to model the missile-target engagement in 2-D using the PNG are the equations (44-55). For this set to be complete, some additional equations concerning the initial conditions on the differential equations have to be considered. A missile employing PNG is fired in a direction to lead the target towards the expected intercept point. The theoretical missile lead angle can be found from the triangle MTI using the law of sines as follows:

$$
\frac{\overline{\mathrm{TI}}}{\sin \left(\varepsilon_{\mathrm{P}}+\Delta_{\varepsilon}\right)}=\frac{\overline{\mathrm{MI}}}{\sin \left(\theta_{\mathrm{T}}+\varepsilon\right)}
$$

Then, the following relation can be obtained

$$
\frac{\mathrm{V}_{\mathrm{T}} \mathrm{t}_{\mathrm{f}}}{\sin \left(\varepsilon_{\mathrm{P}}+\Delta_{\varepsilon}\right)}=\frac{\mathrm{V}_{\mathrm{M}} \mathrm{t}_{\mathrm{f}}}{\sin \left(\theta_{\mathrm{T}}+\varepsilon\right)} \Rightarrow \sin \left(\varepsilon_{\mathrm{P}}+\Delta_{\varepsilon}\right)=\frac{\mathrm{V}_{\mathrm{T}}}{\mathrm{V}_{\mathrm{M}}} \sin \left(\theta_{\mathrm{T}}+\varepsilon\right)
$$

For small $\Delta_{\varepsilon}$, the above equation can be simplified to the following form:

$$
\varepsilon_{\mathrm{P}}=\sin ^{-1}\left[\frac{\mathrm{V}_{\mathrm{T}}}{\mathrm{V}_{\mathrm{M}}} \sin \left(\theta_{\mathrm{T}}+\varepsilon\right)\right]
$$

Practically the missile is not launched exactly on a collision triangle since the expected intercept point is not known precisely. The location of the intercept point can only be approximated because we do not know in advance what the target will do in the future. 
Therefore, an initial angular deviation (heading error $\Delta_{\varepsilon}$ ) of the missile from the collision triangle should be considered i.e.

$$
\begin{aligned}
& \mathrm{V}_{\mathrm{M}_{\mathrm{x}}}(0)=\mathrm{V}_{\mathrm{M}} \cos \left(\varepsilon_{\mathrm{P}}+\Delta_{\varepsilon}+\varepsilon\right) \\
& \mathrm{V}_{\mathrm{M}_{\mathrm{y}}}(0)=\mathrm{V}_{\mathrm{M}} \sin \left(\varepsilon_{\mathrm{P}}+\Delta_{\varepsilon}+\varepsilon\right)
\end{aligned}
$$

The derived equations (44-57) are programmed within the MATLAB environments where the simulation is conducted for different engagement scenarios:

Using target at $\left(\mathrm{x}_{\mathrm{t}}, \mathrm{y}_{\mathrm{t}}\right)=(20,10)[\mathrm{km}]$, moving with velocity $\mathrm{V}_{\mathrm{T}}=0.4[\mathrm{~km} / \mathrm{sec}]$, maneuver $\mathrm{J}_{\mathrm{N}_{\mathrm{T}}}=0\left[\mathrm{~km} / \mathrm{sec}^{2}\right]$, while the missile flight position $\left(\mathrm{x}_{\mathrm{M}}, \mathrm{y}_{\mathrm{M}}=(0,10)[\mathrm{km}]\right)$, velocity $\mathrm{V}_{\mathrm{M}}=1[\mathrm{~km} / \mathrm{sec}]$, and heading error $\Delta_{\varepsilon}=-20\left[^{\circ}\right]$, Fig. 18.

The obtained results for the two cases are compared in view of the proportional navigation gain and include miss distance $\mathrm{D}_{\text {miss }}=36\left[\mathrm{~m}\right.$ ] and time of flight $\mathrm{t}_{\mathrm{f}}=15.1$ [sec] with $\mathrm{N}=3$ while $D_{\text {miss }}=50[\mathrm{~m}]$ and $t_{f}=15[\mathrm{sec}]$ with $\mathrm{N}=5$. The results clarify that larger effective navigation ratio enables the missile to remove the initial heading error more rapidly and thus causing a much tighter trajectory. In addition, the quicker removal of the heading error in the higher navigation ratio case $(\mathrm{N}=5)$ results in larger missile accelerations at the beginning of the flight and lower accelerations near the impact.
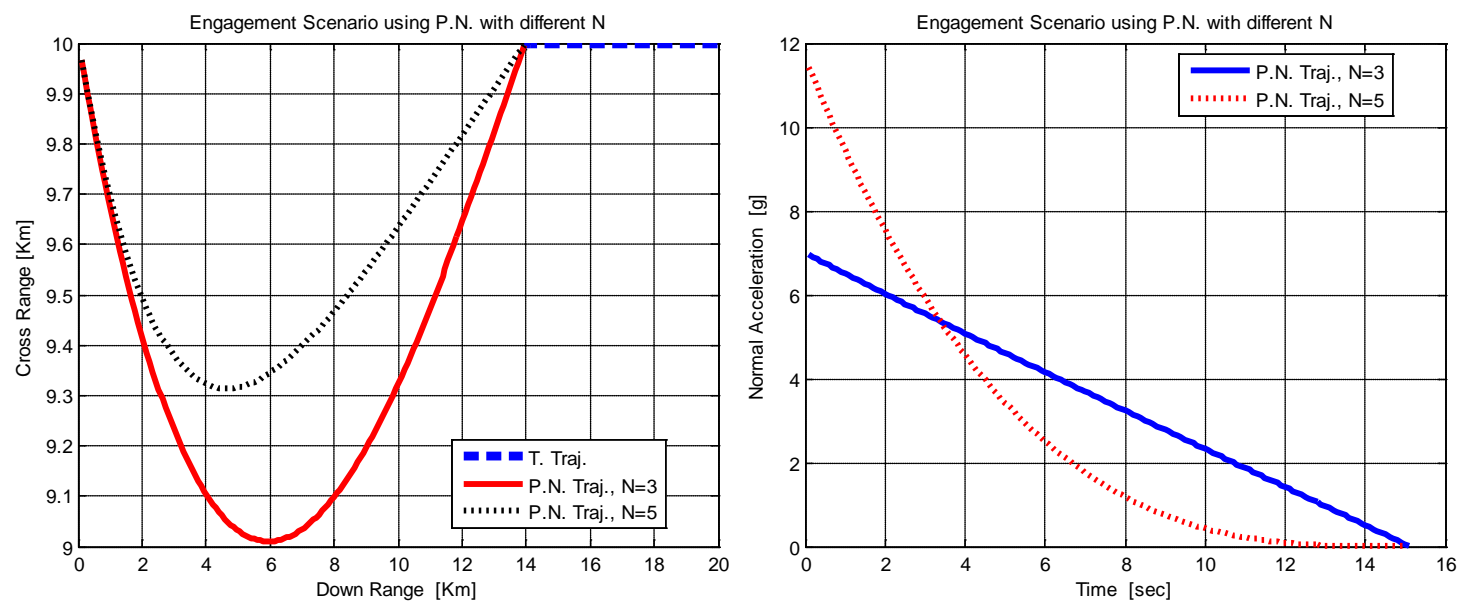

Fig. 18 AA engagement with PN guidance and different navigation ratio

Using maneuverable target at $\left(\mathrm{x}_{\mathrm{t}}, \mathrm{y}_{\mathrm{t}}\right)=(20,10)[\mathrm{km}]$, moving with velocity $\mathrm{V}_{\mathrm{T}}=0.4[\mathrm{~km} / \mathrm{sec}]$, maneuver $\mathrm{J}_{\mathrm{N}_{\mathrm{T}}}=0.03\left[\mathrm{~km} / \mathrm{sec}^{2}\right]$, while the missile flight position $\left(\mathrm{x}_{\mathrm{M}}, \mathrm{y}_{\mathrm{M}}=(0,10)[\mathrm{km}]\right)$, velocity $\mathrm{V}_{\mathrm{M}}=1[\mathrm{~km} / \mathrm{sec}]$, and heading error $\Delta_{\varepsilon}=0.0\left[{ }^{\circ}\right]$, Fig. 19. The obtained results clarify the effect of the navigation ratio $\mathrm{N}$ in case of maneuvering target and show miss distance $\mathrm{D}_{\text {miss }}=88.4[\mathrm{~m}]$ and time of flight $\mathrm{t}_{\mathrm{f}}=15.2[\mathrm{sec}]$ with $\mathrm{N}=3, \mathrm{D}_{\text {miss }}=26.8[\mathrm{~m}]$ and $\mathrm{t}_{\mathrm{f}}=15.2$ [sec] with $\mathrm{N}=5$, and $\mathrm{D}_{\text {miss }}=104\left[\mathrm{~m}\right.$ ] and $\mathrm{t}_{\mathrm{f}}=15.1$ [sec] with $\mathrm{N}=10$. These Figures clarify that larger effective navigation ratio enables the missile to remove the initial heading error more rapidly with larger missile accelerations at the beginning of the flight and lower accelerations near the impact. 

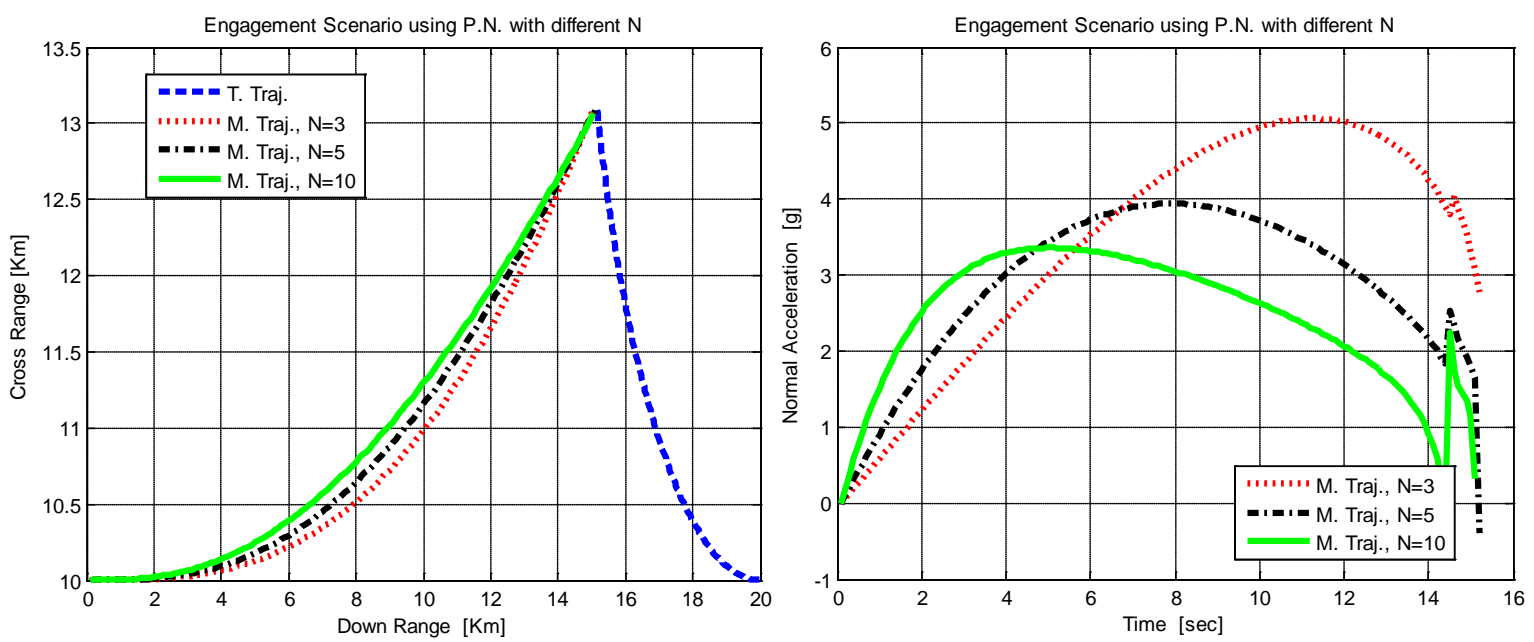

Fig. 19 AA Engagement with PNG and different $\mathbf{N}$ against maneuverable target

Using maneuverable target at $\left(\mathrm{x}_{\mathrm{t}}, \mathrm{y}_{\mathrm{t}}\right)=(20,10)[\mathrm{km}]$, moving with velocity $\mathrm{V}_{\mathrm{T}}=0.4[\mathrm{~km} / \mathrm{sec}]$, maneuver $\mathrm{J}_{\mathrm{N}_{\mathrm{T}}}=0.03\left[\mathrm{~km} / \mathrm{sec}^{2}\right]$, while the missile flight position $\left(\mathrm{x}_{\mathrm{M}}, \mathrm{y}_{\mathrm{M}}=(0,10)[\mathrm{km}]\right)$, velocity $\mathrm{V}_{\mathrm{M}}=1[\mathrm{~km} / \mathrm{sec}]$, navigation gain $\mathrm{N}=5$, and heading error $\Delta_{\varepsilon}=20^{\circ}$.
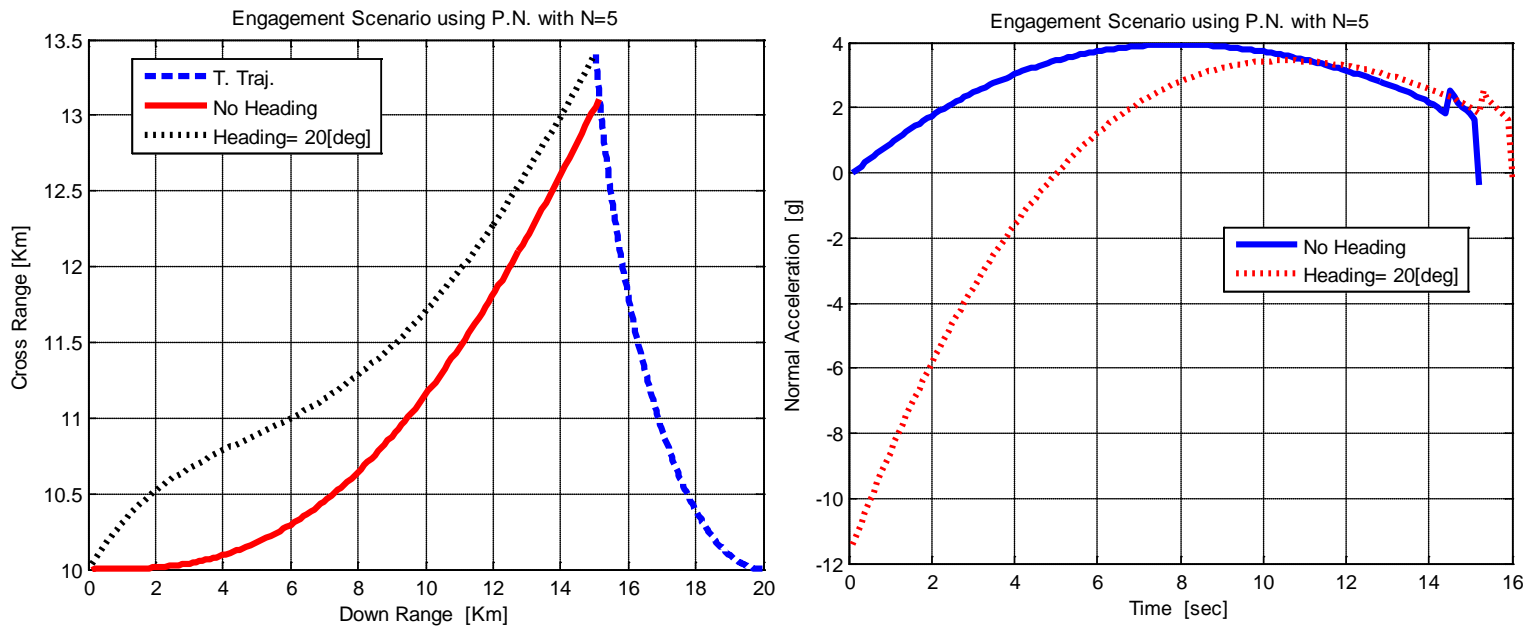

Fig. 20 AA engagement with PNG and different heading error

The obtained results show miss distance $D_{\text {miss }}=26.8[\mathrm{~m}]$ and time of flight $t_{f}=16$ [sec]. The results clarify that the initial heading angle results in larger missile accelerations at the beginning of the flight but achieves lower accelerations near the impact with small miss distance.

\section{Comparative Trajectory Analysis}

\subsection{Comparing the Numerical and Analytic Solutions}

The analytic and numerical approaches for solving the guidance problem using the purepursuit method are compared via conducting the simulation routines with the data $\mathrm{D} 0=30$ $[\mathrm{km}], \varepsilon_{\mathrm{o}}=45^{\circ}, \mathrm{V}_{\mathrm{T}}=0.4[\mathrm{~km} / \mathrm{sec}], \mathrm{V}_{\mathrm{M}}=0.9[\mathrm{~km} / \mathrm{sec}]$ as shown in Fig. 21. 


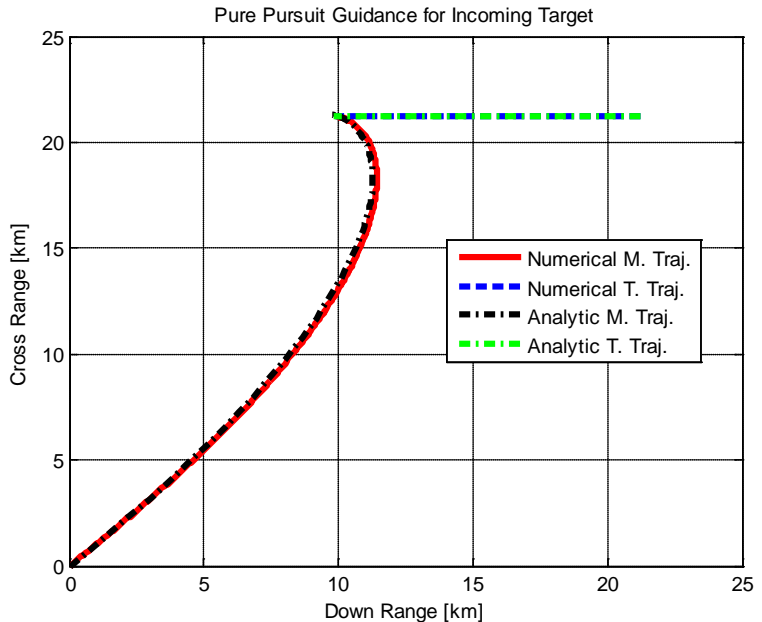

(a)

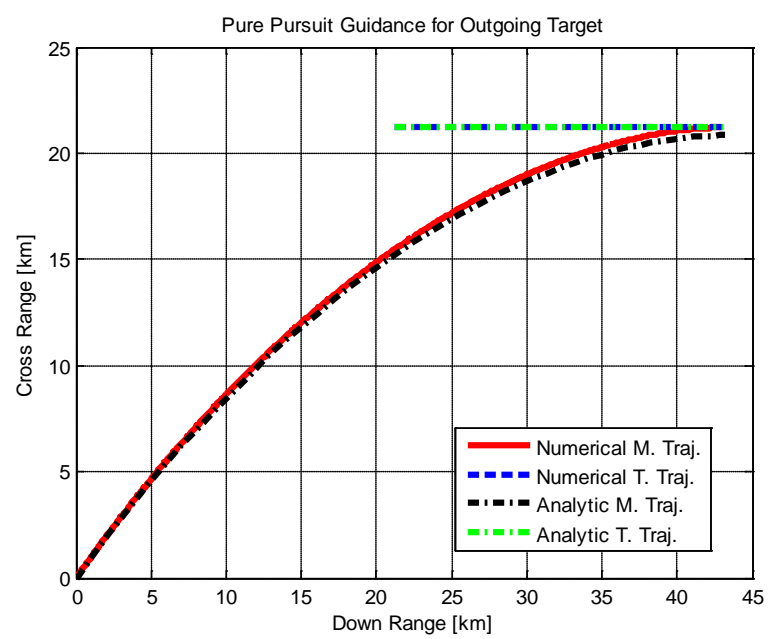

(b)

Fig.21 Flight Trajectory using PPGM (a) incoming and (b) outgoing target

The flight time with approaching (outgoing) target and numerical is $t_{\mathrm{f}}=28.4$ [sec] $\left(\mathrm{t}_{\mathrm{f}}=54.6\right.$ [sec]) while with analytic is $\mathrm{t}_{\mathrm{f}}=28.4842$ [sec] $\left(\mathrm{t}_{\mathrm{f}}=54.5927\right.$ [sec]). The results show no great difference between the numerical and analytical solutions however the numerical approach will be advantageous for the complex and complete guidance system in which case the analytical is impossible.

\subsection{Comparison between Guidance Methods}

For investigating the performance differences between guidance methods, the PPGM and PNGM are considered with the following data: initial target position $\left(\mathrm{X}_{\mathrm{t}}, \mathrm{Y}_{\mathrm{t}}\right)=[130][\mathrm{Km}]$, initial missile position $\left(\mathrm{X}_{\mathrm{m}}, \mathrm{Y}_{\mathrm{m}}\right)=\left[\begin{array}{ll}20 & 0\end{array}[\mathrm{Km}]\right.$, target and missile velocity $\left(\mathrm{V}_{\mathrm{T}}, \mathrm{V}_{\mathrm{M}}\right)=\left[\begin{array}{ll}0.5 & 0.9\end{array}\right]$ $[\mathrm{Km} / \mathrm{sec}]$ and target maneuver $\left(\mathrm{J}_{\mathrm{NT}}\right)= \pm 0.03\left[\mathrm{Km} / \mathrm{sec}^{2}\right]$. Then, the simulation is conducted with different scenarios and yields the trajectories shown in Fig. 22 and Fig. 23.

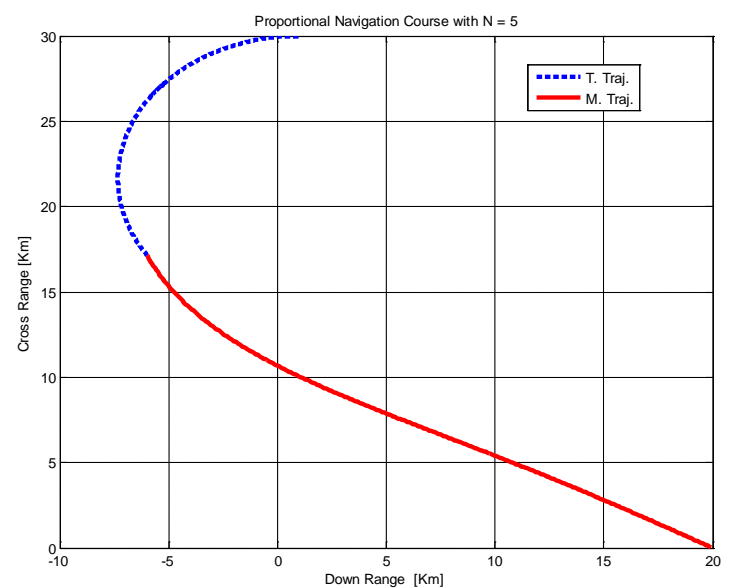

(a)

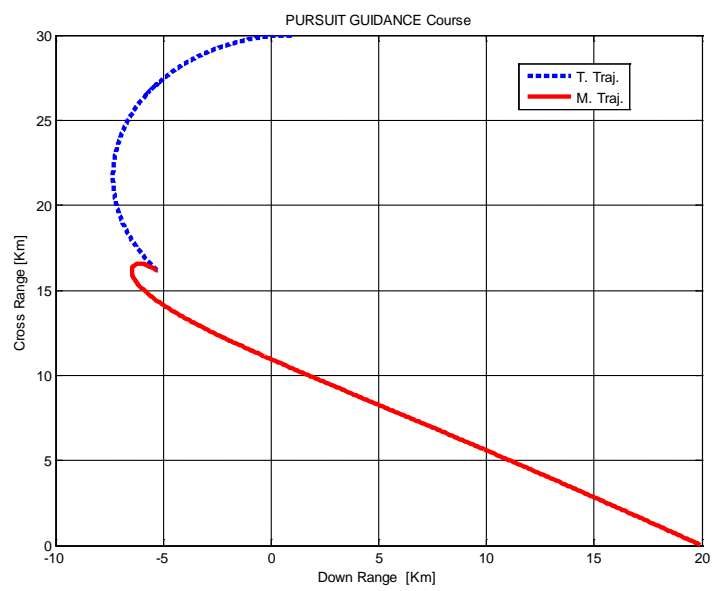

(b)

Fig. 22: Flight Trajectory ( st $^{\text {st }}$ Scenario) using (a) PNGM and (b) PPGM

The results are summarized in the following table;

\begin{tabular}{c|c|c|c|c}
\hline \hline Guidance Method & $\mathrm{D}_{\text {miss }}[\mathrm{m}]$ & $\mathrm{t}_{\mathrm{f}}[\mathrm{sec}]$ & $\mathrm{J}_{\text {Nmax }}\left[\mathrm{km} \backslash \mathrm{sec}^{2}\right]$ & $\mathrm{J}_{\mathrm{Nmax}}[\mathrm{g}]$ \\
\hline \hline PNGM & 9.5 & 35.8 & \pm 0.05 & \pm 5 \\
\hline PPGM & 2.9 & 38.2 & -0.68 & -68 \\
\hline \hline
\end{tabular}




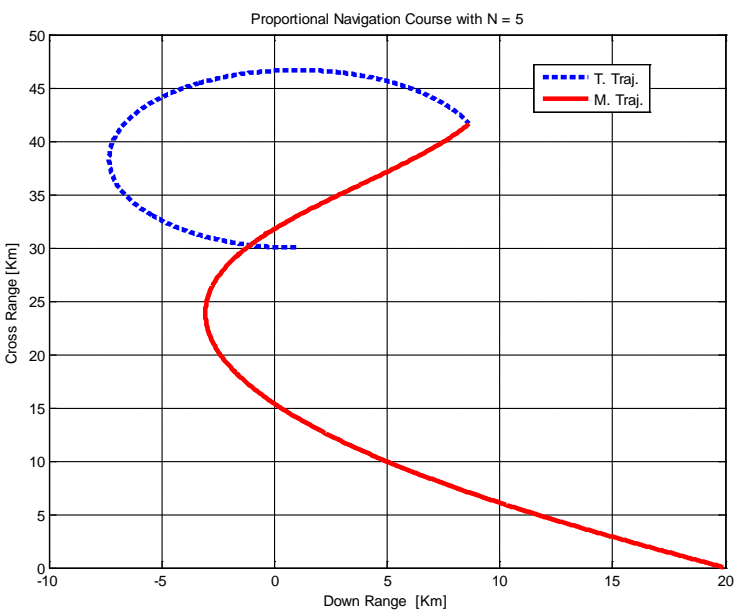

(a)

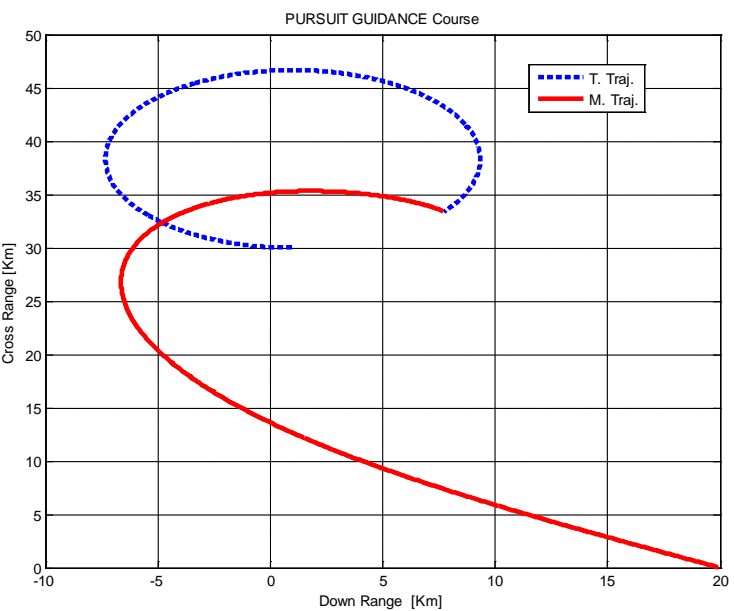

(b)

Fig. 23: Flight Trajectory ( $2^{\text {nd }}$ Scenario) using (a) PNGM and (b) PPGM

The results are summarized in the following table;

\begin{tabular}{c|c|c|c|c}
\hline \hline Guidance Method & $\mathrm{D}_{\text {miss }}[\mathrm{m}]$ & $\mathrm{t}_{\mathrm{f}}[\mathrm{sec}]$ & $\mathrm{J}_{\mathrm{Nmax}}\left[\mathrm{km} \backslash \mathrm{sec}^{2}\right]$ & $\mathrm{J}_{\mathrm{Nmax}}[\mathrm{g}]$ \\
\hline PNGM & 47.4 & 71.7 & \pm 0.042 & \pm 4.2 \\
\hline PPGM & 22.4 & 89.1 & -0.5 & -50 \\
\hline \hline
\end{tabular}

The above results show that the PPGM yields less miss distance however it requires longer flight (11-26 \%) and higher demanded normal acceleration (14 times) than the PNGM.

\section{Conclusions}

The paper presents the kinematics modeling for a homing guided missile system with different guidance methods and approaches for problem solution towards the necessary data for analysis. The obtained results clarify the weakness of the pure pursuit guidance method due to the severe demanded normal acceleration near the impact point especially with approaching and lor maneuvering targets. Using the deviated pursuit guidance with greater heading angle gives less demanded normal acceleration and nearly straight line trajectory. For attacking outgoing (incoming) targets using the deviated pure-pursuit method it is necessary to guide the missile such that the velocity is heading (lagging) the LOS with greater angles as possible $\varepsilon_{\mathrm{p}}\left(-\varepsilon_{\mathrm{p}}\right)$.

The results using the PNGM clarify that larger effective navigation ratio enables the missile to remove the initial heading error more rapidly with larger missile accelerations at the beginning of the flight and lower accelerations near the impact (i.e. can relax the acceleration requirements at interception with the target). The results clarify that the initial heading angle results in larger missile accelerations at the beginning of the flight but achieves lower accelerations near the impact with small miss distance. The magnitude of the initial acceleration is proportional to the heading error and the missile velocity and is inversely proportional to the flight time. The closed form solution of the miss distance is zero i.e. as long as the missile has sufficient acceleration capability; there is no miss due to heading error. Thus, the acceleration capability of the missile should be adequate at the beginning of flight to avoid any possible saturation and consequently failure of the guidance process. In addition, 
the missile acceleration capability should be adequate at the end of flight to avoid controls saturation and can achieve, successfully, the target killing.

The proportional navigation command that is perpendicular to the LOS is not only proportional to the LOS rate and closing velocity but is also proportional to the zero effort miss and inversely proportional to the square of the time-to-go. Consequently, the proportional navigation is considered a general method and can be tailored to the appropriate method via matured guidance law design. The numerical methods are preferred for the guidance problem solution due to its generality and flexibility to cover global engagements with the capability to include different sources of uncertainty. The obtained results showed that the PPGM yields less miss distance however it requires longer flight (11-26\%) and higher demanded normal acceleration (14 times) than the PNGM. Finally, the projection of vectors following the approach (7c) is numerically stable than the others (7a, 7b) as it deals with the absolute values of angles and not differences.

\section{References}

[1]. Acus, R.W., Self-Contained Guidance Technology, AGARD Lecture Series No. 52, pp4.b.1-4.b.18, May 1972.

[2]. Carlo Kopp, Fourth Generation AAMs: The Rafael Python 4, Australian Aviation, April 1997, March 2007.

[3]. Cramer H., Mathematical Methods of Statistics, Princeton University Press, 1951.

[4]. Draper, C.S., Control, Navigation and Guidance, Control Systems Magazine, Dec. 1981, pp4-16.

[5]. Eichblatt, E.J., Test and Evaluation of the Tactical Missile, Vol 119, Progress in Astronautics and Aeronautics, AIAA Tactical Missile Series, 1989.

[6]. El-Sheikh, G.A., Guidance: Theory and Systems, Guidance Department, M.T.C., Cairo, Fourth Ed., 2010.

[7]. El-Sheikh, G.A., Guidance and Control: Tutorial, Technology and Armament Magazine, Cairo, Vol.13-3, July, 1998.

[8]. El-Sheikh, G.A., Guidance Toolbox with Matlab and Simulink, Guidance Department, M.T.C., Cairo, 1998.

[9]. Gerald, C.F., Applied Numerical Analysis, Addison-Wesley, 1978.

[10]. Goodstein, R., Guidance Law Applicability for Missile Closing, AGARD Lecture Series No. 52, pp4.a.1-4.a.6, May 1972.

[11]. Graybeal, W., Simulation: Principles and Methods, Winthrop, 1980.

[12]. Gregory, P.C., General Considerations in Guidance and Control Technology, AGARD Lecture Series No. 52, pp2.1-2.14, May 1972.

[13]. Heap, E., Methodology of Research into Command-Line-of-Sight and Homing Guidance, AGARD Lecture Series No. 52, pp4.d.1.1-4.d.1.9, May 1972.

[14]. James, D.A., Radar Homing Guidance for Tactical Missiles, Macmillan Education Ltd, 1986.

[15]. Kreyszig, E., Advanced Engineering Mathematics, Seventh Edition, John Wiley, 1993.

[16]. Lee, R.G., T.K. Garland-Collins, P. Garnell, D.H.J. Halsey, G.M. Moss, and A.W. Mowat, Guided Weapons: Including Light, Unguided Anti-Tank Weapons, Brassey's Defence Publishers, 1983.

[17]. Lee, R.G., T.K. Garland-Collins, D.E. Johnson, E. Archer, C.Sparkes, G.M. Moss, and A.W. Mowat, Guided Weapons, Brassey’s Defence Publishers, 1988.

[18]. Locke, A.S., Guidance, D. Van Nostrand Company, 1955.

[19]. Maksimov, M.V., Electronic Homing Systems, Translated by W.F. Barton, Artech House, 1988. 
[20]. Maney, C.T., Guidance and Control of Tactical Missiles, AGARD Lecture Series No. 52, May 1972.

[21]. Paarmann, L.D., J.N. Faraone, and C.W. Smoots, Guidance Law Handbook for Classical Proportional Navigation, Lecture Notes, IIT Research Institute, 1968.

[22]. Pitman, D.L., Adjoint Solutions to Intercept Guidance, AGARD Lecture Series No. 52, pp3.b.1-3.b.5, May 1972.

[23]. Shneydor, N.A., Missile Guidance and Pursuit: Kinematics, Dynamics and Control, Horwood Publishing Ltd., 1998.

[24]. Siouris, G.M., Missile Guidance and Control Systems, Springer-Verlag, 2004.

[25]. Sutton, G.P., Rocket Propulsion Elements: An Introduction to the Engineering of Rockets, Sixth Edition, John Wiley \& Sons, 1992.

[26]. Yanushevsky, R., Modern Missile Guidance, CRC Press, (Taylor \& Francis Group), 2008.

[27]. Zarchan, P., Tactical and Strategic Missile Guidance, Second/Fourth Edition, Progress in Astronautics and Aeronautics, 176, AIAA, 1994/1997.

[28]. The Royal Aeronautical Society, The Proceedings: Guidance and Control Systems for Tactical Weapons, London, April 26, 1988. 